\title{
Changes of global gene expression and secondary metabolite accumulation during light-dependent Aspergillus nidulans development
}

\author{
Özgür Bayram ${ }^{\mathrm{a}, 1}$, Kirstin Feussner ${ }^{\mathrm{b}}$, Marc Dumkow ${ }^{\mathrm{a}}$, Cornelia Herrfurth ${ }^{\mathrm{b}}$, Ivo Feussner ${ }^{\mathrm{b}}$, \\ Gerhard H. Braus ${ }^{\mathrm{a}, *}$
}

a Department of Molecular Microbiology and Genetics, Georg-August-Universität, Grisebachstr. 8, D-37077 Göttingen, Germany

${ }^{\mathrm{b}}$ Department of Plant Biochemistry, Georg-August-Universität, Justus-von-Liebig-Weg 11, D-37077 Göttingen, Germany

\section{A R T I C L E I N F O}

\section{Article history:}

Received 21 August 2015

Revised 29 December 2015

Accepted 6 January 2016

Available online 7 January 2016

\section{Keywords:}

Aspergillus nidulans

Development

Light regulation

Conidiation

Sexual development

Gene expression

Secondary metabolism

\begin{abstract}
A B S T R A C T
Fungal development and secondary metabolite production are coordinated by regulatory complexes as the trimeric velvet complex. Light accelerates asexual but decreases sexual development of the filamentous fungus Aspergillus nidulans. Changes in gene expression and secondary metabolite accumulation in response to environmental stimuli have been the focus of many studies, but a comprehensive comparison during entire development is lacking. We compared snapshots of transcript and metabolite profiles during fungal development in dark or light. Overall 2.014 genes corresponding to $19 \%$ of the genome were differentially expressed when submerged vegetative hyphae were compared to surface development. Differentiation was preferentially asexual in light or preferentially sexual connected to delayed asexual development in dark. Light induces significantly gene expression within the first $24-48 \mathrm{~h}$ after the transfer to surfaces. Many light induced genes are also expressed in dark after a delay of up to two days, which might be required for preparation of enhanced sexual development. Darkness results in a massive transcriptional reprogramming causing a peak of lipid-derived fungal pheromone synthesis ( $p s i$ factors) during early sexual development and the expression of genes for cell-wall degradation presumably to mobilize the energy for sexual differentiation. Accumulation of secondary metabolites like antitumoral terrequinone A or like emericellamide start under light conditions, whereas the mycotoxin sterigmatocystin or asperthecin and emodin appear under dark conditions during sexual development. Amino acid synthesis and pool rapidly drop after 72-96 h in dark. Subsequent initiation of apoptotic cell-death pathways in darkness happens significantly later than in light. This illustrates that fungal adaptation in differentiation and secondary metabolite production to light conditions requires the reprogramming of one fifth of the potential of its genome.
\end{abstract}

(c) 2016 Elsevier Inc. All rights reserved.

\section{Introduction}

Multicellular development of eukaryotic organisms is a complex process that requires coordinated orchestration of gene expression. Numerous environmental signals influence the developmental responses of most organisms. One global environmental signal that determines the way of life on earth is light where chlorophyll bearing organisms harvest the photon derived energy. In fungi, light can affect growth, the mode of reproduction or the sporulation rate (Bayram et al., 2010; Corrochano, 2011; Rodriguez-Romero et al., 2010). Most fungi are sessile with a

\footnotetext{
* Corresponding author.

E-mail address: gbraus@gwdg.de (G.H. Braus).

1 Present address: Department of Biology, Maynooth University, National University of Ireland, Co., Kildare, Ireland.
}

saprobic and often plant associated life style. They decay organic materials and produce small chemicals also named secondary metabolites (SM) with bioactive potential (Brakhage, 2013; Keller et al., 2005). Genes coding for the synthesis of SM are frequently organized in gene clusters, which are often localized in subtelomeres of fungal chromosomes and are mostly silenced under normal laboratory conditions. SM gene clusters can be activated in response to environmental signals, in the presence of other organisms or during fungal development (Schroeckh et al., 2009).

The filamentous fungus Aspergillus nidulans is widely used as a model system for eukaryotic genetics and SM. This mold reacts to light by adapting its reproduction style. Germination of asexual or sexual spores on appropriate substrates leads to vegetative hyphae, which are initially incompetent to react to environmental triggers (Etxebeste et al., 2010). When developmental competence is established, the fungus can receive and respond to 
environmental signals such as light, $\mathrm{CO}_{2}$ or $\mathrm{pH}$. Growth under light predominantly leads to conidiophores carrying asexual spores also called conidia, which are released into the air. In the absence of a light signal, asexual development is delayed and the fungus undergoes primarily the sexual cycle. This results in the establishment of sexual fruiting bodies named cleistothecia containing meiotically formed ascospores. The cleistothecia are the overwintering structures of the fungus in the soil. The sharp response to the light signal is a consequence of millions years of evolutionary adaptation under illumination by the sun. Short term light exposure (30 min) results in a differential gene expression of $5 \%$ of the $A$. nidulans genome (Ruger-Herreros et al., 2011). The light signal is sensed by a variety of light receptors sensitive to daylight ranging from short $(350 \mathrm{~nm})$ to long $(650 \mathrm{~nm})$ wavelengths. The visible light (350-650 nm) is sensed by four types of light receptors: (I) phytochrome FphA (red light receptor), (II) white-collar homologs LreA/LreB (blue light receptors), (III) cryptochrome-photolyase like protein CryA (UVA and blue light), (IV) fungal opsin NopA (green light receptor) (Bayram et al., 2008a; Blumenstein et al., 2005; Purschwitz et al., 2008). Red and blue light receptors FphA/LreA\&LreB physically interact with each other and control light responses. FphA is responsible for repression of cleistothecia formation under red light conditions, whereas blue light receptors LreA and LreB repress the cleistothecia formation under blue light illumination (Purschwitz et al., 2008). The exact molecular function of NopA is yet unknown.

A. nidulans produces up to 30 groups of SMs among which the polyketide mycotoxin sterigmatocystin (ST) of the aflatoxin family and the non-ribosomal peptide antibiotic penicillin are the most prominent examples. Many metabolites have been recently identified from A. nidulans including emericellin, emericellamide A-F, emodin, shamixanthone, benzaldehyde or orsellinic acid and its derivatives (Chiang et al., 2010; Giles et al., 2011; MarquezFernandez et al., 2007; Sanchez et al., 2010, 2011).

Fungal development and production of SMs are coordinated by the trimeric velvet complex, composed of VelB-VeA-LaeA, that activates the sexual development and ST production in the absence of light (Bayram et al., 2008b)). Light inhibits formation of the heterotrimeric complex by preventing nuclear accumulation of the VeA bridging component. The VeA-VelB velvet domain heterodimer acts as fungal kingdom specific transcription factor structurally similar to mammalian NF-kappaB; LaeA is a S-adenosyl methionine (SAM) dependent methyltransferase required for the activation of SM gene clusters (Ahmed et al., 2013; Bok and Keller, 2004; Sarikaya Bayram et al., 2010). VipC and VapB represent additional methyltransferases, which are part of a novel VapA-VipC-VapB membrane complex which controls an accurate light response and affects secondary metabolism at the epigenetic level (Sarikaya-Bayram et al., 2014).

Other triggers of morphogenesis in A. nidulans include lipid derived hormones precocious sexual inducer, ( $p s i$ factors), which act similar to local prostaglandin hormones of mammals or jasmonates in plants. The fungal oxylipins are involved in the control of the ratio of asexual and sexual sporulation (Tsitsigiannis and Keller, 2006; Tsitsigiannis et al., 2005). ppoA and ppoC encode two dioxygenases that are involved in the biosynthesis of two antagonistic psi factors. The gene product of $p p o A$ converts the fatty acids to their 8-monohydroperoxy and 5,8-dihydroxy derivatives and is required for sexual development, whereas the gene product of $p p o C$ promotes asexual development (Brodhun et al., 2009; Tsitsigiannis and Keller, 2006; Tsitsigiannis et al., 2004a). Deletion of either gene results in a shift towards opposite developmental program.

Reactive oxygen species (ROS) are internal signals that are required for accurate morphogenesis. There are several enzymes involved in the generation and detoxification of ROS molecules. Various metabolic reactions as well as special enzymes can pro- duce ROS. For example NADPH-oxidase (NoxA) generating superoxide molecules from hydrogen peroxide is required for sexual differentiation in A. nidulans as well as other fungi (Dirschnabel et al., 2014; Lara-Ortiz et al., 2003). The exact developmental functions of ROS scavenging and oxidative response enzymes including catalases or superoxide dismutases remain to be shown.

Cellular amino acid levels are essential for fungal development (Hoffmann et al., 2001). Any perturbation in the cellular amino acid pool causes developmental deficiencies such as small microcleistothecia that are devoid of sexual ascospores. Deletion or overexpression of cross pathway control, $c p c A$ encoding the central transcription factor for amino acid biosynthesis leads to growth defects during amino acid starvation (Eckert et al., 1999; Hoffmann et al., 2001).

In this study, we addressed the global changes in gene expression and metabolite accumulation in response to light during fungal morphogenesis. A detailed transcriptome and non-targeted metabolome analysis as well as the analysis of psi factors of the early and late stages of development resulted in comprehensive insights into the developmental responses of $A$. nidulans. Fungal development requires primary metabolism during vegetative growth, which ensures constant energy supply for the later developmental stages. Asexual and sexual sporulation of the fungus consumes the biomass and energy accumulated during vegetative growth. Starvation during asexual and sexual development triggers the formation of secondary metabolites that protect the next generation of fungal life forms.

\section{Materials and methods}

\subsection{A. nidulans strains, growth media and culturing conditions}

A. nidulans FGSC A4 Glasgow wild type strain (Fungal Genetics Stock Center (University of Missouri, Kansas City, MO, USA) was used as single strain for all performed experiments in this work. FGSC A4 possesses no auxotrophic markers and bears the wild type $v e A$ gene required for the development and SM production. The wild type strain FGSC A4 was grown in glucose minimal medium (GMM) (0.52 g l ${ }^{-1} \mathrm{KCl}, 0.52 \mathrm{~g} \mathrm{l}^{-1} \mathrm{MgSO}_{4}, 1.52 \mathrm{~g} \mathrm{l}^{-1} \mathrm{KH}_{2} \mathrm{PO}_{4}, 0.1 \%$ trace element solution, $\mathrm{pH} 6.5$ ) containing $1 \%$ glucose as carbon source. Vegetative mycelia were obtained from submerged liquid cultures inoculated with $10^{6}$ spores $/ \mathrm{ml}$ and grown on rotary shaker for $20 \mathrm{~h}$ at $37^{\circ} \mathrm{C}$. They were washed $(0.96 \% \mathrm{NaCl})$, filtered through miracloth and shifted to solid GMM to developmentally synchronize the cultures. Cultures were induced $24 \mathrm{~h}$ (A24) and $48 \mathrm{~h}$ (A48) for asexual development under white fluorescent light

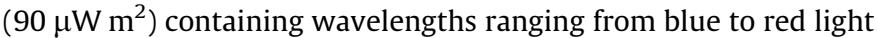
(400-700 nm). Cultures induced for sexual development were cultivated for $24 \mathrm{~h} \mathrm{(S24),} 48 \mathrm{~h}$ (S48), $72 \mathrm{~h} \mathrm{(S72)}$ and $96 \mathrm{~h}$ (S96) in the darkness. For sexual cultures, plates were wrapped with parafilm to limit oxygenation and further induce the sexual development.

\subsection{Microscopic analysis}

A. nidulans colonies, hyphae, asexual and sexual structures were taken with a Kappa PS30 digital camera (Kappa opto-electronics, Germany) used in combination with a Zeiss Axiolab (Zeiss AG, Germany) light microscope or an Olympus SZX12 binocular (Olympus GmbH, Germany).

\subsection{Transcriptome analysis}

\subsubsection{Sequence analysis}

Sequences from $A$. nidulans were retrieved from the National Center For Biotechnology Information (NCBI, gi: 40747330), from 
Broad Institute Aspergillus Comparative Database and Aspergillus Genome Database (AspGD) (Galagan et al., 2005). Homolog sequences from other organisms also retrieved from the NCBI Entrez Protein, Broad and AspGD database (Nierman et al., 2005; Wei et al., 2007). Sequence comparisons were performed for different criteria e-value, score, conserved domains and thus predicted functions.

\subsubsection{RNA extraction and quality control}

Harvested mycelia from $A$. nidulans cultures induced for different developmental stages were frozen in liquid nitrogen and grounded immediately. Total RNA was extracted from $2 \mathrm{mg}$ grounded culture using TrizolTM reagent (Invitrogen, Germany) as recommended by the manufacturer. Crude RNA preparations were dissolved in $250 \mu$ diethyl pyrocarbonate (DEPC)-treated water at $65{ }^{\circ} \mathrm{C}$ for $12 \mathrm{~min}$. Phenolic precipitation of the RNA probes were performed twice. RNA probes were mixed with one volume phenol/chloroform/isoamylalcohol (25 v/24v/1 v) and centrifuged $\left(13,000 \mathrm{~g}, 30 \mathrm{~min} ; 4^{\circ} \mathrm{C}\right)$. Aqueous phase was mixed with one volume isopropanol and $20 \mu \mathrm{l}$ sodium acetate $(3 \mathrm{M})$ and placed for $30 \mathrm{~min}$ at $-20^{\circ} \mathrm{C}$. After centrifugation $\left(13,000 \mathrm{~g}, 30 \mathrm{~min}, 4^{\circ} \mathrm{C}\right)$ pellet was washed twice with $75 \%$ ethanol. The dried pellets were dissolved in $200 \mu \mathrm{l}$ DEPC-treated water at $65^{\circ} \mathrm{C}$ for $15 \mathrm{~min}$. RNA concentration were measured by NanoDrop ND-1000. Absorbance ratios A260/A280 and A230/A260 indicating the purity/quality of the samples were determined to be higher than 2.0 for both ratios. RNA was stored at $-80^{\circ} \mathrm{C}$ in $20 \mu$ laliquots. Integrity and composition of the isolated RNA was checked using Bio-analyzer 2100 (Agilent Technologies, USA).

\subsubsection{Microarray platforms and processing}

The TIGR A. nidulans version 1 microarrays employed throughout this work contained two replicates with 23,962 oligomers in total (TIGR, J. Craig Venter Institute, USA). A. nidulans version 1 microarrays were used for transcriptome analysis on the first biological replicate of FGSC A4 grown for different periods of sexual and asexual development as well as for the $20 \mathrm{~h}$ vegetatively grown culture. DNA microarray hybridization was performed according to the Amino Allyl MessageAmpII aRNA Kit (Ambion Life Technologies, USA, Cat. N: 1753). $1 \mu \mathrm{g}$ purified RNA was used for first and second strand cDNA synthesis. aaRNA was labeled with Cyanine3 (Су3) and Cyanine5 (Cy5) dyes (Amersham Bioscience, USA). Washed microarray slides were dried through acetonitrile. G2505B Microarray Scanner and program analyzed slides (Agilent Technologies, USA). For the confirmation of expression data on the first biological replicate with TIGR A. nidulans microarray version 1 , sensitive Agilent Technology custom microarray system was used. This platform was used for the second biological replicate. The ordered custom arrays comprised 10,560 gene transcripts with 35,353 gene exons derived from Cadre based on the third annotation. However three to four independent oligomers per gene provide the opportunity to calculate mean values inside this system. A scoring system for the quality of the spotted 60-mer oligomers revealed high specificity to the gene exons. $2 \mu \mathrm{g}$ total RNA from a second biological replicate derived from $A$. nidulans wild type strain FGSC A4 was applied to first strand cDNA (copy DNA) synthesis by Low RNA Input Linear Amplification Kit, PLUS, two color (Agilent Technologies, USA, Cat. N: 5188-5340). Procedure was performed as recommended by the corresponding protocol. After first strand cDNA synthesis, cDNA was directly transcribed to cRNA and cRNA immediately Cy3 or Cy5 labeled, respectively. Labeled cRNA was purified using RNeasy RNA purification Kit (Qiagen, Germany). Yield and concentration of purified labeled cRNA was determined through NanoDrop. $0.825 \mu \mathrm{g}$ of each Cy3-labeled cRNA derived from a defined developmental time point was mixed with $0.825 \mu$ g Cy5-labeled pool cRNA for hybridization with A. nidulans whole genome custom arrays. Hybridized arrays were washed and analyzed through G2505B Microarray Scanning Unit (Agilent Technologies, USA).

\subsubsection{Microarray experimental design and statistical analysis}

For the TIGR based transcriptional profiling of $A$. nidulans FGSC A4 wild type strain during different developmental stages B-swap design with four microarrays was used for comparisons. Microarray intensity data were extracted using the "Automatic Image Processing for Microarrays" software. Normalization of the raw intensity data was performed with a non-linear Loess regression method (Yang et al., 2002). Differentially expressed genes were identified by an ANOVA fixed effects model (Landgrebe et al., 2004) and adjusted p-values were obtained by the BenjaminiHochberg method to control the False Discovery Rate (Benjamini and Hochberg, 1995; Bretz et al., 2005). Normalization and statistical computation was performed for two independent datasets derived from a high gain and a low gain scan, allowing replacement of saturated features in the high gain scan with data from the low gain measurement. Contrasts refer to $\log 2$ normalized intensity ratios between the samples of the different developmental stages. Genes with $\log 2$ ratios $\geqslant \pm 1.5$ and adjusted $p$ values $\leqslant 0.01$ in both biological replicates and platforms were regarded as differentially expressed. In order to analyze the Agilent based transcriptional profile of the second biological replicate on A. nidulans FGSC A4 wild type strain during different developmental stages, each stage was compared and hybridized with a RNA pool generated by RNA of each point of time (Fig. 1). Three technical replicates per comparison were prepared. Agilent Feature Extraction 9.1 was used for microarray intensity extraction. Single microarrays were normalized with a non-linear Loess regression method. Normalization among the microarrays was performed with Variance Stabilized Normalization (VSN) (Huber et al., 2002). For determination of differentially expressed genes, statistical tests were carried out employing Limma. p-values adjusted as previously described (Smyth, 2004). All computations were performed with the statistical software 'R' (http://cran.r-project.org/).

\subsubsection{Data mining for transcriptome analysis}

In order to sort data by their functionality, gene probes were annotated manually by homology searches via translated nucleotide BLAST algorithm (blastx) at NCBI (http://www.ncbi.nlm.nih.gov/BLAST). A functional category was assigned to the gene probe only if the best scoring hit with a known or predicted function showed an alignment score of 100 in total or higher and expect value e-8 or lower. The exception was the "unknown" category, to which no gene probes were assigned due to the low score values in homology searches. These probes had certain homology to other proteins. Genes being involved in processes apart from the shown categories were added to the "other" category. Genes without indicated domain was sorted into the "no domain" category. Each gene probe was assigned to one functional category only.

Raw expression data derived from TIGR and Agilent transcriptomes are stored at http://wwwuser.gwdg.de/ imgarchi/001_ $1271826434 /$. Braus 4 and 5 folders include analysis folders where html folders contain comparative data for each developmental stages. The Bilder folder in Braus 4 and 5 folders include the raw scan data from laser scanner. One expression value for each gene was generated from TIGR microarrays and four expression values were generated from Agilent customized microarrays. A simplified list for all differentially expressed genes with $-1,0$ and 1 description was also added. Analyzed data from manual annotation and categorization for differentially expressed genes concerning the whole transcriptome, the development specific and delayed genes were also stored. These lists were subdivided into data showing 


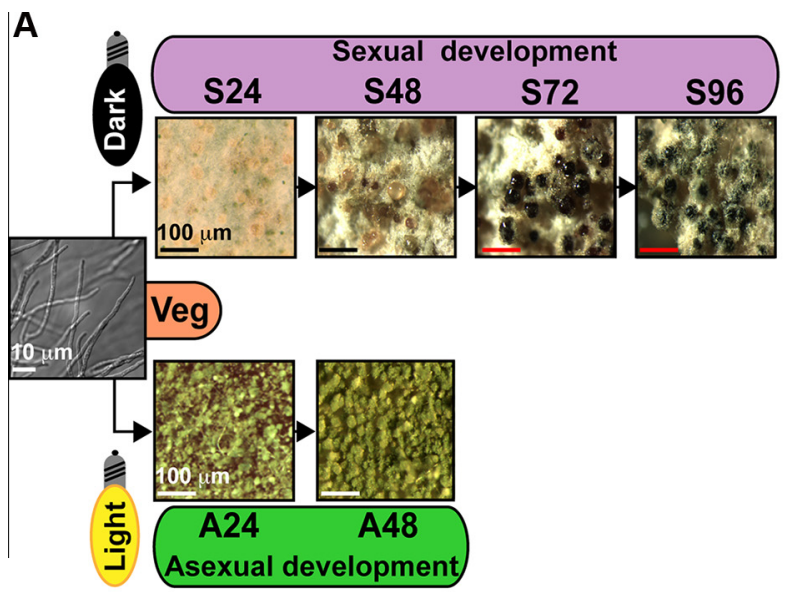

B

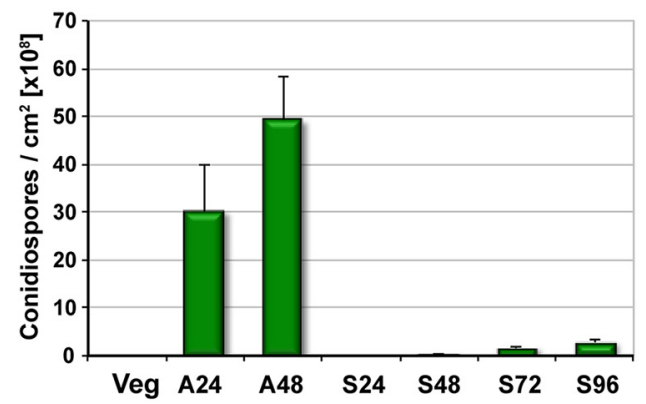

C

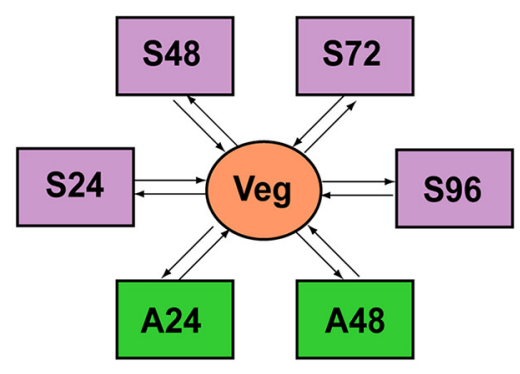

D

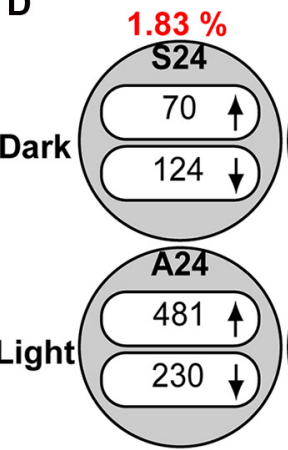

$6.73 \%$

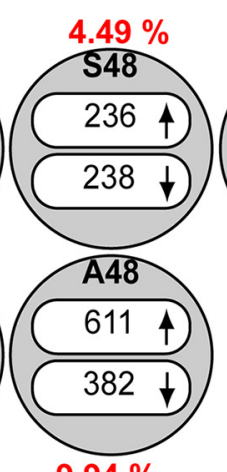

$9.94 \%$

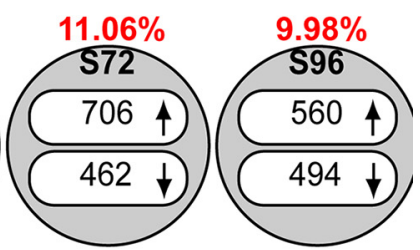

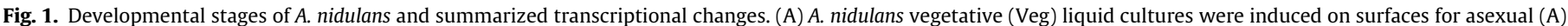

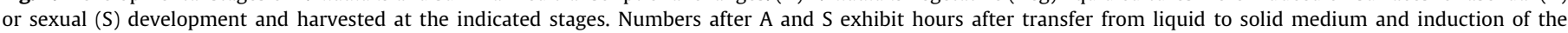

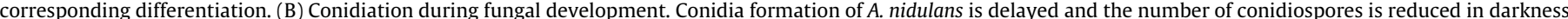

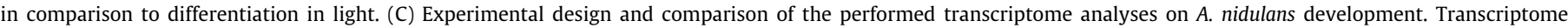

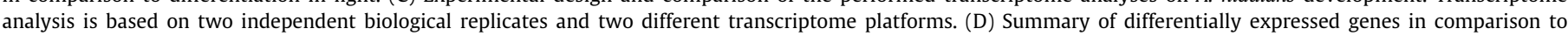

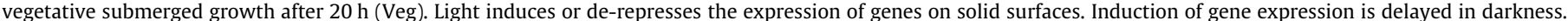

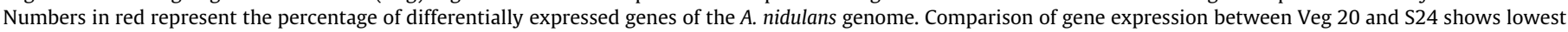

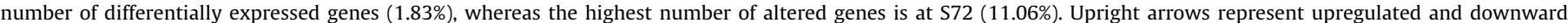

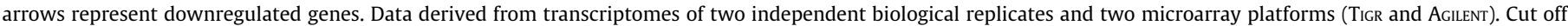
was set to $\log 2 \geqslant \pm 1.5$. (For interpretation of the references to color in this figure legend, the reader is referred to the web version of this article.)

the different analyses. Different time points were compared, overlapping data are presented and a summary reveals an overview on the numbers of all differentially expressed genes for each category.

\subsection{Metabolome analysis}

\subsubsection{Metabolite fingerprinting by UPLC ESI-TOF-MS}

For non-targeted metabolite fingerprinting of the intracellular metabolome, $A$. nidulans wild type A4 was cultivated and harvested as described above for transcriptome analysis. A. nidulans for endpoint extracellular metabolome was cultivated differentially. Therefore, $8 \times 10^{6}$ conidiospores were inoculated into horizontal flasks filled with 1.51 liquid minimal medium as it was used for transcriptome analysis. Flasks with sexually induced $A$. nidulans cultures were closed with parafilm and covered with a double layer aluminum foil. After $48 \mathrm{~h}$ asexual and $96 \mathrm{~h}$ sexual induction culture supernatant were harvested by centrifugation and immediately frozen with liquid nitrogen. Two biological replicates of two independent experiments were used for the analysis of mycelium and supernatant from vegetative, asexual and sexual cultures. Two-phase extraction were performed with methyl-tertbutylether according to Matyash (Matyash et al., 2008) with modifications for the extraction of supernatant (Floerl et al., 2012). The fingerprinting analysis was conducted for the polar as well as the non-polar extraction phase by Ultra Performance Liquid Chromatography (ACQUITY UPLC-System, Waters Corporation, USA) coupled with an orthogonal time-of-flight mass spectrometer (LCT Premier, Waters Corporation, USA). For LC an ACQUITY UPLC-BEH SHIELD RP18 column $(1 \times 100 \mathrm{~mm}, 1.7 \mu \mathrm{m}$ particle size $)$ was used at a temperature of $40{ }^{\circ} \mathrm{C}$, a flow rate of $0.2 \mathrm{ml} / \mathrm{min}$ and with the following gradients: polar extraction phase: $0-0.5 \mathrm{~min}$ $0 \%$ B, $0.5-3$ min from $0 \%$ B to $20 \%$ B, 3-6 min from $20 \%$ B to $99 \%$ B, 6-9.5 min 99\% B and 9.5-13 min 40\% B; non-polar extraction phase: $0-0.5 \mathrm{~min} 40 \% \mathrm{~B}, 0.5-5.5 \mathrm{~min}$ from $40 \% \mathrm{~B}$ to $99 \% \mathrm{~B}, 5.5-$ $10 \mathrm{~min}$ from $99 \% \mathrm{~B}$ to $100 \% \mathrm{~B}$ and $10.1-13 \mathrm{~min} 40 \%$ (solvent system A: water/methanol/acetonitrile/formic acid (90:5:5:0.1, $v / v / v /$ $v)$; B: acetonitrile/formic acid (100:0.1, v/v)). The TOF-MS was operated in negative as well as positive electrospray ionization (ESI) mode in $\mathrm{W}$ optics and with a mass resolution larger than 10,000. Data were acquired by MassLynx software (Waters Corporation, Milford, USA) in centroided format over a mass range of $\mathrm{m} / \mathrm{z}$ $50-1200$ with scan duration of $0.5 \mathrm{~s}$ and an interscan delay of $0.1 \mathrm{~s}$. The capillary and the cone voltage were maintained at $2700 \mathrm{~V}$ and $30 \mathrm{~V}$ and the desolvation and source temperature at $250{ }^{\circ} \mathrm{C}$ and $80^{\circ} \mathrm{C}$, respectively. Nitrogen was used as cone $(30 \mathrm{l} / \mathrm{h})$ and desolvation gas $(600 \mathrm{l} / \mathrm{h})$. For accurate mass measurement the Dynamic Range Enhancement mode was used for data recording. All analysis were monitored by using Leucine-enkephaline $\left([\mathrm{M}-\mathrm{H}]^{-} 554.2615\right.$ or $[\mathrm{M}+\mathrm{H}]^{+} 556.2771$ as well as its ${ }^{13} \mathrm{C}$ isotopologue $[\mathrm{M}-\mathrm{H}]^{-}$ 555.2615 or its double ${ }^{13} \mathrm{C}$ isotopologue $[\mathrm{M}+\mathrm{H}]^{+} 558.2836$ ) as lock spray reference compound. The raw mass spectrometry data of all samples were processed using the MarkerLynx Application 
Manager for MassLynx software (Waters Corporation, USA) resulting in large data matrices. For further data processing, like filtering, adduct correction, data base search as well as data visualization, clustering and metabolite enrichment analysis the MarVis (MarkerVisualization) toolbox (http://marvis.gobics.de, (Kaever et al., 2015) was used. A Kruskal-Wallis test was performed to extract a subset of 3162 high-quality features of a confidence threshold $<10^{-6}$ for the intracellular metabolome (Supplementary data 3 ) and 3482 features with pVal $<5 \times 10^{-3}$ for the extracellular metabolome (Supplementary data 4 ). The exact mass information of the metabolite features was used for searching public and internal data bases (Kaever et al., 2015). Finally a cluster analysis was performed by training a one-dimensional self-organizing-map (1D-SOM) model for data visualization and analysis (Kaever et al., 2009).

The putative identity of all metabolites of interest has been confirmed by co-elution with identical standards or by MS/MS analysis. For that a LC 1290 Infinity (Agilent Technologies, Santa Clara, USA) coupled with a 6540 UHD Accurate-Mass Q-TOF LC MS instrument with Agilent Jet Stream Technology as ESI source (Agilent Technologies, USA) has been used. For LC an ACQUITY UPLC BEH SHIELD RP18 column $(2.1 \times 100 \mathrm{~mm}, 1.7 \mu \mathrm{m}$ particle size, Waters Corporation, USA) was used at $40^{\circ} \mathrm{C}$, a flow rate of $0.5 \mathrm{ml} / \mathrm{min}$, and a solvent system and gradient comparable with that for non-targeted analysis. The Q-TOF MS instrument was operated for positive and negative ionization in the targeted MS/MS mode with a detection frequency of $2 \mathrm{GHz}$. The following source conditions has been used: gas temperature: $250{ }^{\circ} \mathrm{C}$; drying gas flow: $8 \mathrm{l} / \mathrm{min}$; nebulizer pressure: $35 \mathrm{psi}$; sheat gas temperature: $300{ }^{\circ} \mathrm{C}$; sheat gas flow: $8 \mathrm{l} / \mathrm{min}$; VCap voltage: $3000 \mathrm{~V}$; nozzle voltage: $200 \mathrm{~V}$; fragmentor voltage: $100 \mathrm{~V}$. For exact mass measurement the reference mass correction with trifluoroacetic acid $\left([\mathrm{M}-\mathrm{H}]^{-} 112.98559\right)$ and $\mathrm{HP}-921\left(\left[\mathrm{M}+\mathrm{CH}_{2} \mathrm{O}_{2}-\mathrm{H}\right]^{-}\right.$966.00073) were used. The MassHunter Workstation Acquisition software B.04.00 as well as the MassHunter Qualitative Analysis software B.05.00 (Agilent Technologies, USA) was used for data acquisition and analysis, respectively. The data analysis tool VANTED has been used for data representation of the secondary metabolites (Junker et al., 2006).

\subsubsection{Psi-factor extraction and analysis by GC MS}

For comprehensive metabolite analyzes at Veg, A24, A48, S24, S48, S72 and S96 A. nidulans wild type strain was cultured with two independent biological replicates as for transcriptome analyzes. In order to analyze psi-factors, $0.6 \mathrm{~g}$ of frozen and ground A. nidulans cells were extracted by adding $8 \mathrm{ml}$ of extraction medium (n-hexane/2-propanol $(3: 2, v / v)$ with $0.0025 \% \mathrm{w} / \mathrm{v}$ butylated hydroxytoluene) and $13 \mathrm{C} 18-8-\mathrm{HOD}$ as internal standard. The extract was shaken for $10 \mathrm{~min}$ and centrifuged at $3200 \mathrm{~g}$ at $4{ }^{\circ} \mathrm{C}$ for $10 \mathrm{~min}$. After collecting the clear upper phase, a $6.7 \%(w / v)$ solution of potassium sulfate was added up to a volume of $13 \mathrm{ml}$. Drying of the upper hexane-rich layer under streaming nitrogen was subsequently followed by the vigorous shaking and centrifugation at $3200 \mathrm{~g}$ at $4{ }^{\circ} \mathrm{C}$ for $10 \mathrm{~min}$. The remaining lipids were re-dissolved in $0.4 \mathrm{ml}$ methanol and methylated after addition of $380 \mu \mathrm{l}$ methanol and $6.5 \mu \mathrm{l}$ trimethylsilyldiazomethane. After shaking for $30 \mathrm{~min}, 0.2 \mu \mathrm{l}$ of glacial acetic acid was added. The corresponding methyl esters were dried under streaming nitrogen and redissolved in $80 \mu \mathrm{l}$ methanol/water/acetic acid (75:25:0.1, $v / v / v)$. At first, psi-factors were purified on reversed phase HPLC on an ET250/2 Nucleosil $120-5$ C18 column $(2.1 \times 250 \mathrm{~mm}, 5 \mu \mathrm{m}$ particle size; Macherey-Nagel, Germany) assembled in an Agilent 1100 HPLC system coupled to a diode array detector. The solvent systems were as follows: solvent system A: methanol/water/acetic acid $(75: 25: 0.1, v / v / v)$; and solvent system B: methanol/acetic acid $(100: 0.1, v / v)$. The gradient elution profile was as follows: flow rate of $0.18 \mathrm{ml} / \mathrm{min}, 0-5 \mathrm{~min}, 100 \% \mathrm{~A} ; 5-10 \mathrm{~min}$ from $100 \%$ A to $100 \% \mathrm{~B}$ and flow rate increase to $0.36 \mathrm{ml} / \mathrm{min} ; 10-20 \mathrm{~min}, 100 \% \mathrm{~B} ; 20$ 25 min from $100 \%$ B to $100 \%$ A; and $25-30$ min, $100 \%$ A and flow rate decreased to $0.18 \mathrm{ml} / \mathrm{min}$. For purification of psi-factors, eluate fraction was collected between 8 and $13.5 \mathrm{~min}$ and dried under streaming nitrogen. The residue of this fraction was re-dissolved in $3 \mu \mathrm{l}$ acetonitrile. After addition of $1 \mu \mathrm{l}$ pure N,O-bis(trimethylsilyl) trifluoroacetamide (Sigma, Germany), analysis of trimethylsilyl ethers/methyl esters of psi-factors was carried out using an Agilent 5973 network mass selective detector connected to an Agilent 6890 gas chromatograph (Agilent Technologies, USA) equipped with a capillary DB- 23 column $(30 \mathrm{~mm} \times 0.25 \mathrm{~mm} ; 0.25 \mu \mathrm{m}$ coating thickness; J\&W Scientific, USA and Agilent Technologies, USA). Helium was used as a carrier gas at a flow rate of $1 \mathrm{ml} / \mathrm{min}$. The temperature gradient was $150{ }^{\circ} \mathrm{C}$ for $1 \mathrm{~min}, 150-200{ }^{\circ} \mathrm{C}$ at $4 \mathrm{~K} \mathrm{~min}^{-1}, 200-250^{\circ} \mathrm{C}$ at $5 \mathrm{~K} \mathrm{~min}^{-1}$, and $250^{\circ} \mathrm{C}$ for $6 \mathrm{~min}$. Electron energy of $70 \mathrm{eV}$, an ion source temperature of $230^{\circ} \mathrm{C}$ and a temperature of $260{ }^{\circ} \mathrm{C}$ for the transfer line was used. For quantification, the ions $m / z 241$ (8-HOE; $\mathrm{Rf}=11.41 \mathrm{~min}), \mathrm{m} / \mathrm{z} 250\left({ }^{13} \mathrm{C} 18-8-\right.$ HOD; $\mathrm{Rf}=11.75 \mathrm{~min}), \mathrm{m} / \mathrm{z} 239(8-\mathrm{HOD} ; \mathrm{Rf}=11.76 \mathrm{~min})$ and $\mathrm{m} / \mathrm{z}$ 271 (10-HOD; Rf=12.18 min), were used. Standard curves were constructed by analyzing known mixtures of unlabeled psifactors and ${ }^{13} \mathrm{C} 18-8-\mathrm{HOD}$ and plotting the ratios of ion intensities (ion of unlabeled/ion of ${ }^{13} \mathrm{C}$-labeled) vs. the molar amount of unlabeled.

\section{Results}

\section{1. $19 \%$ of the A. nidulans transcriptome is differentially expressed during light dependent development}

Coordination of fungal development and SM production require an accurate dynamic orchestration of gene expression. Transcriptome analyses of an A. nidulans wild type (FGSC A4, veA+) were performed to determine differentially expressed genes during various developmental stages (Fig. 1A and B, Supplementary data 1: Tables S1 and S2). The standard to determine differential gene expression during development represented the vegetative fungus, which was grown as hyphae in submerged shake cultures for $20 \mathrm{~h}$ after spore germination (Veg; 20 h; Fig. 1C). Shake cultures represent undifferentiated version of the fungus. Development and differentiation were monitored and analyzed after the transfer of the fungus on solid medium. Two different illumination conditions were tested which resulted in distinct developmental phenotypes. (i) Without light and increased $\mathrm{CO}_{2}$ levels sexual development is promoted and completed after four days where each day samples were analyzed (S24, S48, S72, S96). Asexual development is delayed in comparison to illumination conditions (Fig. 1B). (ii) Continuous light favors and accelerates asexual development. Transcriptomes were determined one or two days after the transfer when mature conidia as air-borne asexual spores were formed (A24, A48). In total, $19.1 \%$ of the genes of the genome of $A$. nidulans (2.014 of 10.560 genes) were differentially expressed during development in comparison to vegetative hyphae (Fig. 1C) by using cut off value $\log 2 \geqslant \pm 1.5$. At $24 \mathrm{~h}$ after the transfer from liquid medium to plates only a weak response was monitored in differential gene expression in cultures without illumination favoring sexual development (S24). Developmental structures were hardly visible at this time point (Fig. 1A) and only $1.83 \%$ of the transcriptome corresponding to 194 genes were differentially expressed with most of them (124 genes) even downregulated (Fig. 1D).

At S72 stage of development, more than half (58\%, 1168 genes) of the differentially expressed genes (total list of genes differentially expressed in any of the treatments) were up- or downregulated. In other words, more than $11 \%$ of the genome of $A$. 
nidulans was differentially expressed at S72. In contrast, light results in an immediate induction of gene expression with a significantly stronger impact on the fungal transcriptome in comparison to the cultures, which were kept in darkness. The number of differentially expressed genes after $24 \mathrm{~h}$ of illumination to favor asexual development (A24, 711 genes, $6.73 \%$ of whole genome) was 3.7fold higher than in the corresponding culture kept in dark (S24, 194 genes, $1.83 \%$ of whole genome).

In summary, the expression data suggest that most drastic changes in gene expression (S72) require a $48 \mathrm{~h}$ time window/shift after the transfer from liquid to solid media in darkness. Development is retarded by two days in darkness resulting in sexual ascospore formation combined with a delay in conidia formation (S72 and S96). However, in the light, fungal development and differentiation are immediately induced by light resulting in asexual sporulation (A24, A48).

\subsection{Light}

\subsubsection{Light triggers significant expressional changes at 24-48 h that are absent in darkness}

Differential gene expression in the presence or absence of light was further dissected to analyze the changes in metabolism and morphogenesis by a functional classification of the transcriptome. Eleven defined categories like primary metabolism, secondary metabolism, redox enzymes or stress and defence were generated as previously described (Nahlik et al., 2010).

Similar numbers of genes of primary metabolism are upregulated in the presence of light at $48 \mathrm{~h}$ (A48) compared to darkness at $72 \mathrm{~h}$ (S72) (Fig. 2) which includes several general pathways of carbohydrate, lipid or amino acid metabolism (Supplementary data 5 ). There is a significant difference in the downregulation of primary metabolism transcripts when A48 (74 genes) and S72 (103 genes, Fig. 2B) were compared. The number of downregulated amino acid biosynthetic genes was higher in darkness during sexual development at S72 (34 genes) versus 19 genes in A48, whereas similar numbers ( 25 vs. 23 amino acid biosynthetic genes) were upregulated at A48 and S72. In parallel with the downregulation of amino acid biosynthetic genes at late sexual development (S72 and S96), 88 upregulated secondary metabolite genes peaked at late sexual development (S72, Fig. 2B).

Since $A$. nidulans development is a light-dependent process, genes regulated by light are of special interest. Therefore, we compared the gene expression profiles between $24 \mathrm{~h}$ and $48 \mathrm{~h}$ stages of development in the presence (A24 and A48) or absence (S24 and S48) of light (Fig. 3). 32 up- and 50 downregulated overlapping genes were present in dark at both $24 \mathrm{~h}$ stages (A24, S24; Fig. $3 \mathrm{~A}$ and $\mathrm{B})$. However, this number further increased when both $48 \mathrm{~h}$ developmental points were compared. There were 148 upand 167 downregulated genes that overlap in light and dark conditions. In contrast to the early development in darkness (S24 and S48), the light response (A24 and A48) caused more drastic alterations in gene expression. Light specifically initiated expression of a group of specific genes that are closely associated with asexual development in A. nidulans. These asexual genes involved in transcription, signal transduction and development were upregulated at both asexual stages (A24 and A48). Beside the known essential asexual regulators such as transcription factors (TF) brlA (AN0973) and wetA (AN1937) further yet uncharacterized TFs were specifically upregulated at asexual development. These TFs contain $\mathrm{C}_{2} \mathrm{H}_{2}$ finger domain protein and $\mathrm{Zn}(2)-\mathrm{Cys}(6)$ DNA binding domain proteins that are similar to characterized regulators such as $S$. cerevisiae PIP2, SIP4 homologs (AN6747 and AN3433), S. pombe MOC3 homolog AN5924 and AflR-like Zn(2)-Cys(6) protein AN7072, as well as uncharacterized transcription factors such as $\mathrm{Zn}(2)-\mathrm{Cys}(6)$ DNA binding domain containing TF (AN2677), $\mathrm{C}_{2} \mathrm{H}_{2}$ finger
AN4586, and bZIP TF (AN8643) (Fig. 3C). In contrast, only one S48 specific Zn(2)-Cys(6) TF (AN2650) could be identified.

A neighboring gene of wetA was also upregulated at this stage and codes for a putative MAPK interacting protein with GPIanchor (AN1941) involved in fruiting body formation and host attack in plant pathogenic fungi. Putative cytosolic $\mathrm{Cu} / \mathrm{Zn}$ superoxide dismutase (SOD, AN1131) was already present at early asexual development and might trigger asexual development through hydrogen peroxide generation at this stage. Functional categorization of stage specific genes showed an increased number of upregulated transporter genes in comparison of both $48 \mathrm{~h}$ stages (Fig. 4). 18 asexually and two sexually upregulated transporter genes were detectable, indicating that $A$. nidulans initiates a massive secretion or transportation during asexual sporulation, which might be required for coating of asexual conidia.

These data suggest that the presence of the light signal immediately results in strong responses, which alter gene expression during asexual development, whereas without a light trigger early sexual development is characterized by a prolonged latent phase of hardly changed gene expression.

\subsubsection{Light-dependent gene expression coding for polysaccharide} degradation provide energy supply during development of $A$. nidulans

A. nidulans fungus can mobilize carbon sources from its own cell wall which can serve as storage compartment which is required for development (Wei et al., 2001, 2004; Zonneveld, 1971, 1972, 1974). In addition, the fungus has a saprophytic life style that requires growth on decaying organic matters. Therefore, $A$. nidulans expresses numerous genes required for usage of plant and bacterial cell wall glucans as well as peptidoglycans and stored polysaccharides including starch or lichenins (Table 1 ).

Most of the cell wall degrading enzymes were already expressed at vegetative stage. It seems to be important for the fungus to get energy from the extracellular environment since it has to store substantial amounts of carbohydrates for the construction of novel cell walls specific for asexual and sexual development. There is presumably an important difference between genes required only for vegetative filamentous growth and genes whose expression is initiated during vegetative growth at the establishment of developmental competence and continues during differentiation to support asexual and/or sexual differentiation. In total, 14 genes for saprophytic life cycle were expressed during vegetative growth. pmeA (AN3390) encodes a pectinesterase (Bauer et al., 2006; Coutinho et al., 2009) and was expressed at vegetative stage exclusively (Table 1 ). Expression of 13 out of the 14 vegetatively expressed genes persisted during differentiation. Two of these genes code for muramidases (AN6470, AN8969), which are able to hydrolyze bacterial cell walls. Nine genes, which were expressed at vegetative stage, encode hydrolyzing enzymes for plant cell wall. The rest of the genes belong to following categories: five xylan hydrolyzing enzymes (xgcA AN1542, AN2359, AN7158, $x \ln B$ AN9365), two cutinases (AN10346, AN7541), xgcA an end-specific cellobiohydrolase (AN1542), three pectin hydrolyzing enzymes (abfB AN1571, pgaB AN4372) and a glycosyl hydrolase family 61 with cellulose binding domain (AN7891). Additionally, xgeA (AN2385) encodes a GPI-anchored licheninase already expressed at vegetative stage of $A$. nidulans. Lichenins serve as energy storage and are polysaccharides found in lichen, moos and few plants.

Genes for polysaccharide degrading enzymes specific for asexual development include three additional hydrolases for extracellular glucans, xylans and cutins, respectively. A secreted, extracellular endo-1,3(4)- $\beta$-glucanase (AN3883), which might be required for hydrolysis of the cell wall of other fungi or plants, was expressed at both asexual stages A24 and A48. A ferulic acid esterase faeC (AN5267) and a putative cutinase (AN7180) 


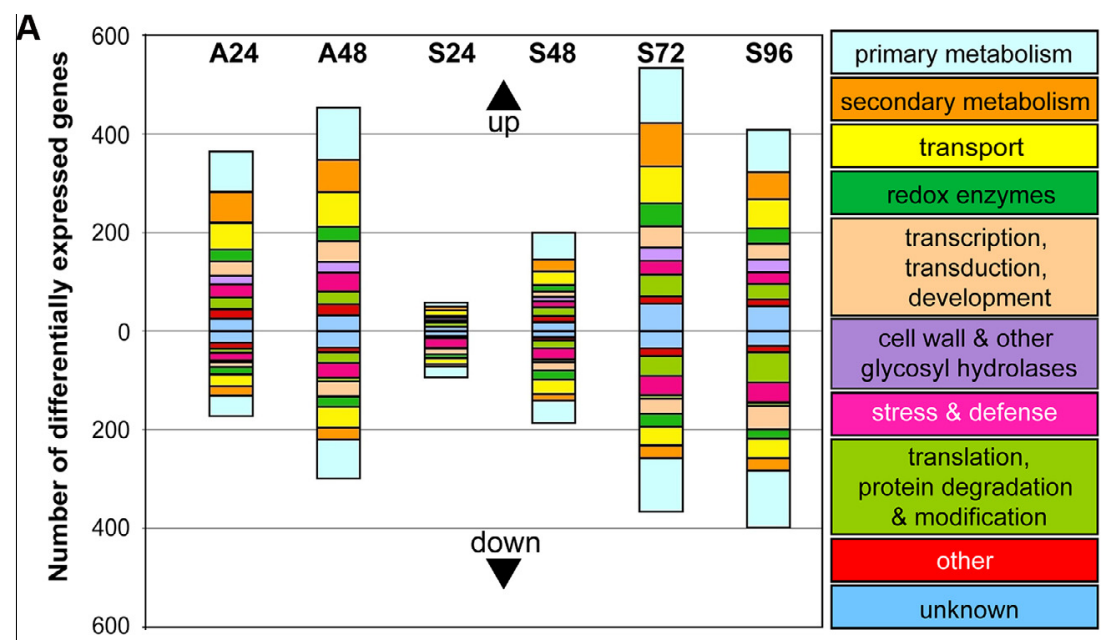

B
\begin{tabular}{|lcccccc|}
\hline upregulated genes & $\mathbf{A 2 4}$ & $\mathbf{A 4 8}$ & $\mathbf{S 2 4}$ & $\mathbf{S 4 8}$ & $\mathbf{S 7 2}$ & $\mathbf{S 9 6}$ \\
\hline primary metabolism & 78 & 100 & 8 & 52 & 101 & 78 \\
\hline secondary metabolism & 62 & 65 & 7 & 24 & 88 & 54 \\
transport & 54 & 70 & 12 & 28 & 75 & 59 \\
\hline redox enzymes & 24 & 29 & 2 & 13 & 46 & 31 \\
transcription, signal transduction ... & 30 & 43 & 1 & 11 & 43 & 32 \\
cell wall \& glycosyl hydrolases & 22 & 28 & 6 & 11 & 37 & 34 \\
\hline stress and defense & 26 & 38 & 4 & 12 & 29 & 25 \\
translation, protein degradation \& modificati & 24 & 26 & 9 & 18 & 44 & 31 \\
\hline other & 19 & 22 & 1 & 12 & 15 & 14 \\
\hline unknown & 25 & 32 & 9 & 18 & 55 & 50 \\
no domain (not shown in A) & 117 & 158 & 11 & 37 & 173 & 152 \\
\hline TOTAL & 481 & 611 & 70 & 236 & 706 & 560 \\
\hline downregulated genes & $\mathbf{A 2 4}$ & $\mathbf{A 4 8}$ & $\mathbf{S 2 4}$ & $\mathbf{S 4 8}$ & $\mathbf{S 7 2}$ & $\mathbf{S 9 6}$ \\
\hline primary metabolism & 37 & 74 & 21 & 44 & 103 & 109 \\
secondary metabolism & 19 & 24 & 6 & 13 & 26 & 25 \\
transport & 24 & 42 & 12 & 29 & 38 & 40 \\
\hline redox enzymes & 14 & 20 & 7 & 19 & 25 & 18 \\
transcription, signal transduction ... & 10 & 31 & 11 & 17 & 31 & 47 \\
cell wall \& glycosyl hydrolases & 9 & 12 & 3 & 7 & 12 & 13 \\
\hline stress and defense & 15 & 30 & 18 & 23 & 39 & 41 \\
translation, protein degradat \& modification & 8 & 22 & 3 & 16 & 40 & 61 \\
\hline other & 12 & 10 & 3 & 6 & 16 & 13 \\
\hline unknown & 24 & 35 & 9 & 13 & 35 & 30 \\
no domain (not shown in A) & 58 & 82 & 31 & 51 & 97 & 97 \\
TOTAL & 230 & 382 & 124 & 238 & 462 & 494 \\
\hline
\end{tabular}

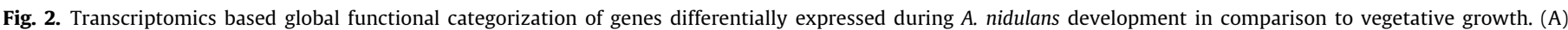

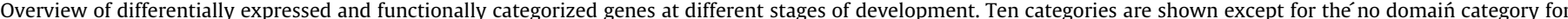

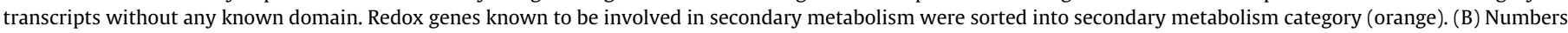

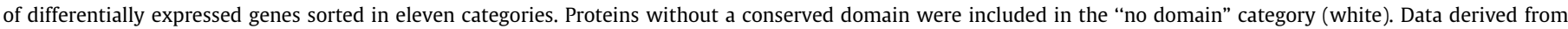
transcriptomes of two independent biological replicates and two microarray platforms. Cut off was set to $\log 2 \geqslant \pm 1.5$.

hydrolyzes plant xylans (Bauer et al., 2006; Coutinho et al., 2009) were expressed at A48.

In contrast to asexual stage, the fungus expresses two additional bacterial cell wall hydrolases (AN0543; AN8466) at late sexual development S72 and S96 (Table 1). Both uncharacterized enzymes contain a lysine domain (LysM motif) known from peptidoglycan hydrolases with peptidoglycan binding site (PFAM). Among the eight sexual specific genes for saprophytic life cycle there were four pectin hydrolyzing enzymes (AN0711, AN2509, AN8453, AN8891). Three of them were already expressed at early sexual development that exhibits the importance for a quick usage of pectin as energy source for A. nidulans. Xylan and cellulose hydrolases (AN1477, AN5320) was only induced at late sexual development S96. Three of seven known amylases (amyA-amyF, glaA, glaB) were upregulated at the analyzed stages. An amylase already expressed at vegetative stage is encoded by amyD (AN3308). It was downregulated at A48 but remained expressed during the whole sexual cycle. Since the fungus requires further starch mobilization it expresses three additional amylases (glaA, $a m y B$, AN5463) at both developmental cycles. The glucoamylase encoded by AN5463 was upregulated at late stages of both developments (A48 and S72, S96). glaA and amyB revealed similar activation pattern, demonstrating requirement for the usage of starch at the end of both development stages when the fungus suffered from starvation. Only genes for plant cell-wall hydrolyzing enyzmes were expressed during asexual and sexual development (AN0245, AN5282, AN5309, AN6518, AN8890) as well. This suggests that expression of bacterial cell-wall hydrolase genes is inhibited by light and specifically promoted in darkness.

These data suggest that $A$. nidulans expresses after germination early genes for degrading a broad range of carbohydrates. This might be appropriate for surface growth on a variety of organic materials. During sexual development within the soil and in darkness, the fungus activates more specifically enzymes for cell-wall sugars from bacteria and plants, which might provide as well energy as building blocks for specialized cells for sexual development to synthesize fruiting bodies.

\subsubsection{Light-dependent aging process mediated through programmed} cell-death and reactive oxygen species (ROS)

A. nidulans is a sessile saprophytic soil-born fungus which exhausts nutrients within its habitat and subsequently suffers 


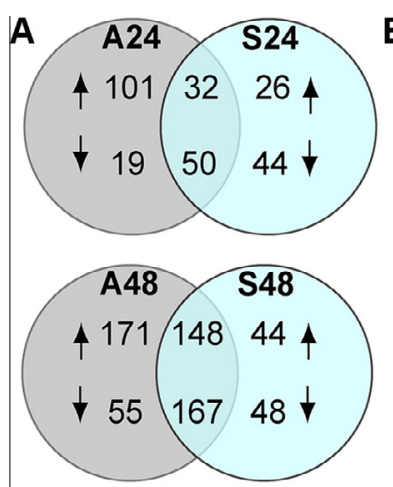

C

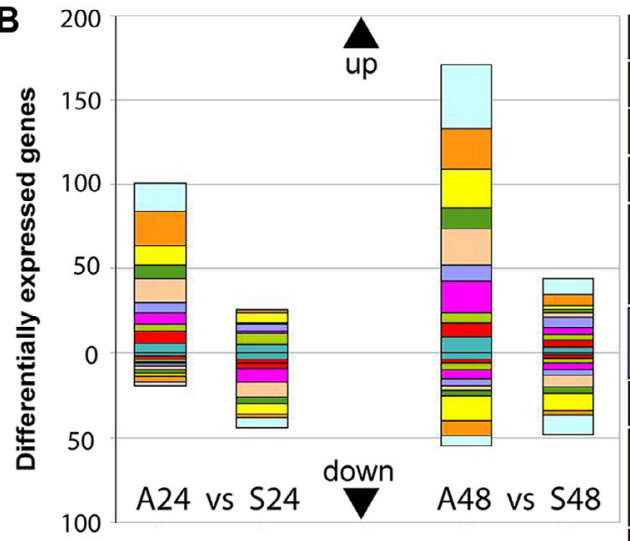

Putative transcription factors influenced by light

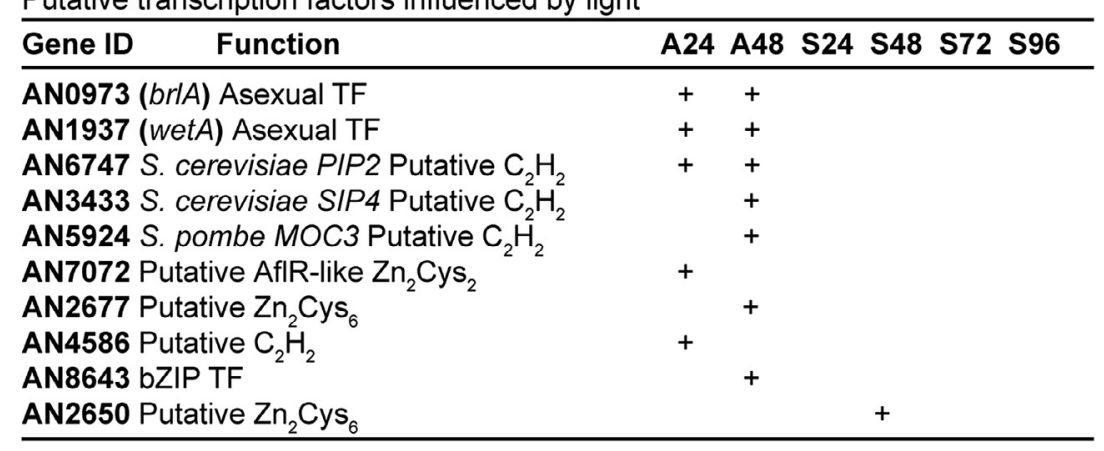

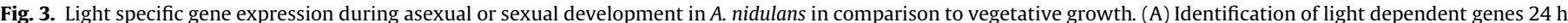

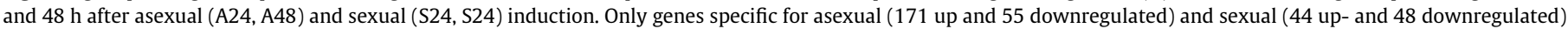

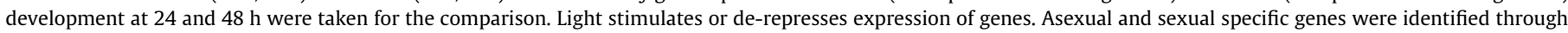

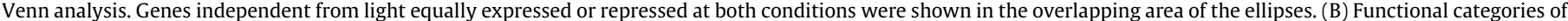

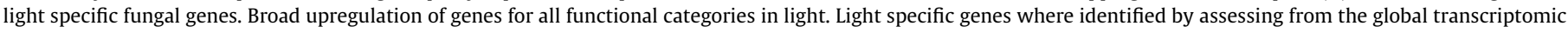

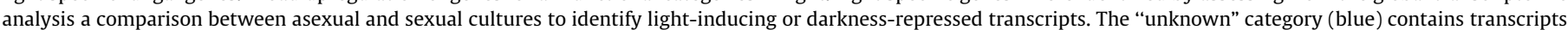

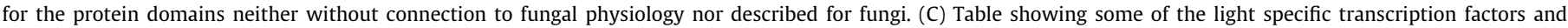
regulators of asexual development.

from nutrient starvation. We analyzed whether and when genes for programmed cell-death were expressed during the aging process which is connected to fungal development. Apoptotic processes were already initiated in light after $24 \mathrm{~h}$ growth after the transfer to solid surface (A24). A yeast apoptosis initiation factor 1 (AIF1) ortholog of A. nidulans (AN9315) was upregulated at A24 (Table 2). Aif1 is a mitochondrial cell death effector that enters the nucleus in response to apoptotic induction/stimuli (Wissing et al., 2004). Generally, as a consequence of mitochondrial alterations during apoptosis, disruption of the electron transport chain leads to an excessive production of ROS (Bras et al., 2005). Indeed maturation of conidiospores was not completed at this stage of asexual development but programmed cell death was clearly induced before the asexual development was finished. A gene for a putative caspase (AN4874) was upregulated at A48 and might be crucial for aging at late asexual stage. Its homolog in S. cerevisiae Rny1p has an endoribonuclease activity and plays a role in cell morphogenesis and apoptosis (MacIntosh et al., 2001; Thompson and Parker, 2009).

Expression of several genes, coding for putative ROS-associated enzymes, was detected during asexual development (Table 2). There are four putative NADPH oxidase (Nox) encoding genes (AN0773, AN10893, AN4906, AN8683) with ferric reductase FADbinding domain (BROAD) and ferric-chelate domain (NCBI/PFAM) in the A. nidulans genome. AN0773 and AN10893 encode Nox enzymes, which were expressed at vegetative growth, might be crucial for initiation of differentiation through $\mathrm{H}_{2} \mathrm{O}_{2}$ and/or $\mathrm{O}_{2}^{-}$ formation. AN0773 was still detectable in asexual development and mid stages of sexual development, whereas AN10893 expression was present at both early asexual and sexual stages (A24, S24, S48).

Additionally, superoxide-dismutases (SOD) catalyzing conversion of superoxide to hydrogen peroxide exhibited development specific expression as well. Putative cytosolic $\mathrm{Cu} / \mathrm{Zn}$ Sod (AN1131) was upregulated during asexual sporulation (A24 and A48). An uncharacterized ferric SOD (AN5148) was expressed already at vegetative stage but the exact molecular function is still unknown. This ferric SOD was slightly downregulated at mid and late sexual development S48, S96, respectively. Since Nox generates superoxides from hydrogen peroxides and SOD catalyzes the reverse reaction, we assigned development specific, antagonistic Nox and Sod based on our transcriptome data. Thus, vegetatively expressed Nox (AN0773, AN10893) could be counterparts of the Fe Sod (AN5148), the sexual specific Nox (AN4906, AN8683) corresponds to the Mn Sod sodM (AN0785), whereas the asexual specific $\mathrm{Cu} / \mathrm{Zn}$ Sod (AN1131) has no corresponding Nox, which indicates another $\mathrm{H}_{2} \mathrm{O}_{2} / \mathrm{O}_{2}^{-}$ratio requirement for asexual development. Catalases catalyze the break-down of hydrogen peroxide into water and oxygen (Chelikani et al., 2004). Beside the identified and described catalases A-C (AN8637, AN9339, AN5918) (Kawasaki and Aguirre, 2001; Kawasaki et al., 1997; Navarro et al., 1996) another sexually expressed catalase (AN8553) was identified (Table 2). The conidiaspecific catalase CatA was expressed at A24 and A48 as described. Expression of $c a t B$, which encodes a hyphal catalase, was indeed 
A
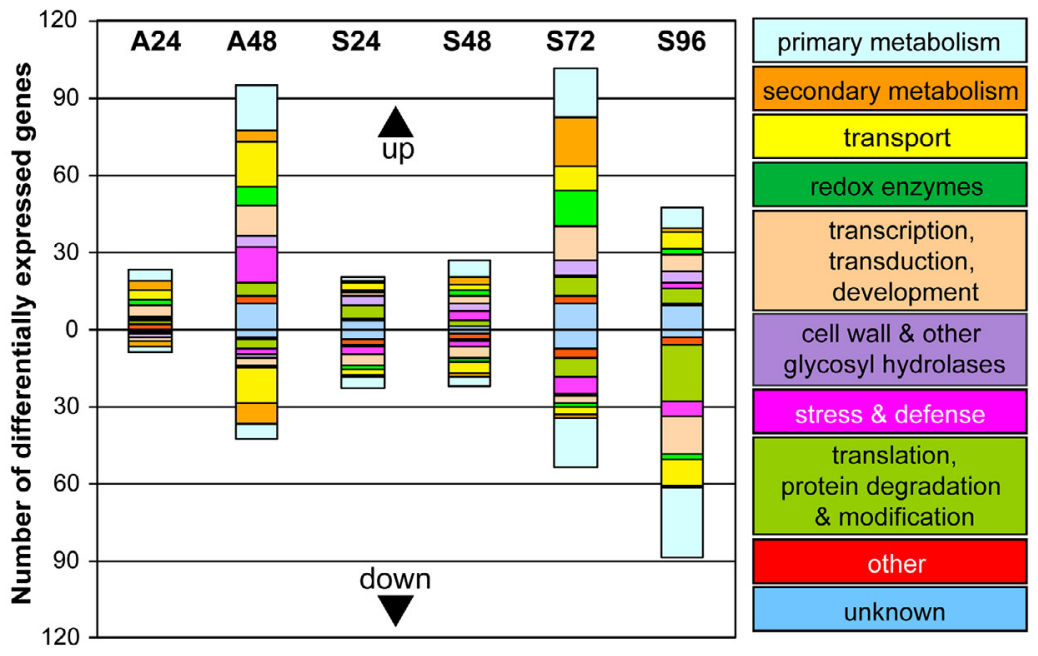

\begin{tabular}{|c|c|c|c|c|c|c|}
\hline upregulated genes & A24 & A48 & S24 & S48 & $\mathbf{S 7 2}$ & S96 \\
\hline primary metabolism & 4 & 18 & & 7 & 19 & 8 \\
\hline secondary metabolism & 4 & 4 & 1 & 3 & 19 & 1 \\
\hline transport & 4 & 18 & 3 & 2 & 9 & 7 \\
\hline redox enzymes & 2 & 7 & 1 & 2 & 14 & 2 \\
\hline transcription, signal transduction . & 4 & 12 & 1 & 3 & 13 & 7 \\
\hline cell wall \& glycosyl hydrolases & 1 & 4 & 1 & 3 & 6 & 4 \\
\hline stress and defense & 1 & 14 & 0 & 4 & 1 & 2 \\
\hline translation, protein degradation & 1 & 5 & 5 & 2 & 7 & 6 \\
\hline other & 2 & 3 & 1 & 0 & 3 & 1 \\
\hline unknown & 0 & 10 & 3 & 1 & 10 & 9 \\
\hline no domain (not shown in A) & 11 & 40 & 2 & 6 & 41 & 27 \\
\hline TOTAL & 34 & 135 & 22 & 33 & 142 & 74 \\
\hline downregulated genes & A24 & A48 & S24 & S48 & S72 & S96 \\
\hline primary metabolism & 2 & 6 & 3 & 2 & 18 & 27 \\
\hline secondary metabolism & 2 & 8 & 1 & 2 & 2 & 1 \\
\hline transport & 0 & 13 & 2 & 4 & 3 & 10 \\
\hline redox enzymes & 0 & 1 & 2 & 2 & 1 & 2 \\
\hline transcription, signal transduction & 2 & 2 & 4 & $\overline{4}$ & 3 & 15 \\
\hline cell wall \& glycosyl hydrolases & $\overline{1}$ & $\overline{0}$ & 0 & 0 & 0 & 0 \\
\hline stress and defense & 0 & 2 & 3 & 2 & 6 & 6 \\
\hline translation, protein degradation & 1 & 4 & 1 & 1 & 8 & 22 \\
\hline other & 0 & 1 & 2 & 2 & 3 & 3 \\
\hline unknown & 1 & 3 & 4 & 1 & 8 & 3 \\
\hline no domain (not shown in $A$ ) & 6 & 18 & 9 & 9 & 20 & 33 \\
\hline TOTAL & 15 & 58 & 31 & 29 & 72 & 122 \\
\hline
\end{tabular}

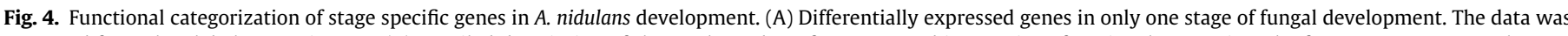

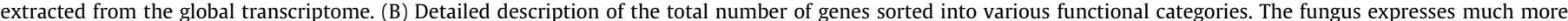

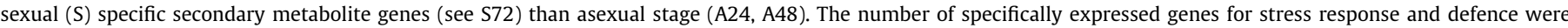

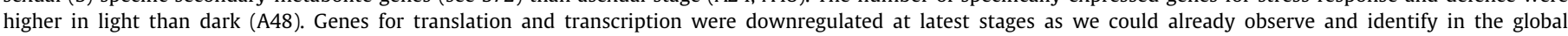
transcriptomic view. Corresponding genes are restricted to the analyzed late sexual stages. Previously stated parameters were used for this transcriptomic extraction.

detectable at vegetative stage but was also found at asexual and sexual development. catB expression decreased at late asexual development (A48) and was present through sexual differentiation. catC was constitutively expressed during development. Interestingly, after catA, AN8553 represents a second asexual specific catalase.

These results suggest that the fungus initiates apoptotic processes during asexual development and apparently mobilizes numerous ROS scavenging enzymes to get rid of the ROS toxicity produced predominantly during asexual growth under high oxygen and solar radiation. They also suggest that the fungus controls ROS levels carefully to keep cellular damages as low as possible and thereby assure proper regulation to successfully finalize the developmental cycle.

\subsection{Dark}

\subsubsection{Late sexual development in dark (S72 and S96) requires} significant alterations in gene expression of A. nidulans transcriptome

A deepened understanding of differences in developmental responses requires the characterization of stage specific changes in gene expression. Therefore, genes specific for vegetative, asexual and sexual development/stage were depicted (Fig. 4). As for the general transcriptome also most of the differentially expressed stage specific genes were present at middle or late stages of asexual and sexual development (A48, S72 and S96). A total of 58 stage specific genes were downregulated at A48, 72 genes at $S 72$ and 122 genes at S96, respectively (Fig. 4B).

Most specifically upregulated genes in sexual development (142 genes) were present at S72, when cleistothecia maturation was not yet finished and the ascospores were being produced. In contrast, by a large fold induction of upregulated genes in asexual development (135 genes) appeared at A48 when asexual differentiation was already completed. These data suggest that even after very late asexual development, fungal cells or spores prepare for the future habitats by accumulating or expressing transcripts of various genes.

Most stage specific SM genes (19) were expressed at S72 (Fig. 4B). For instance, four genes of the monodictyphenone $(m d p)$ gene cluster ( $m d p C$ (AN0146), $m d p L$ (AN10023), $m d p I$ (AN10035) and $m d p K(A N 10044)$ ) were expressed $72 \mathrm{~h}$ after 
Table 1

Selected genes mediating plant and bacterial cell wall and plant polysaccharide hydrolysis to assure energy supply during A. nidulans development.

\begin{tabular}{|c|c|c|c|c|c|c|c|}
\hline Gene ID & Function & $\mathrm{A} 24$ & A48 & S24 & S48 & S72 & S96 \\
\hline \multicolumn{8}{|c|}{ Cell wall degradation of plant and bacteria } \\
\hline AN3390 & pmeA, pectinesterase ${ }^{a}$ & - & - & - & - & - & - \\
\hline \multicolumn{8}{|c|}{ Already at vegetative stage } \\
\hline AN10346 & Cutinase & - & & & & & \\
\hline AN1542 & $x g c A$, end-specific cellobiohydrolase $\mathrm{a}^{\mathrm{a}}$ & - & - & & - & - & - \\
\hline AN1571 & $a b f B$, alpha-arabinofuranosidase $\mathrm{a}^{\mathrm{a}}$ & - & - & & & & - \\
\hline AN2359 & xylan 1,4-beta-xylosidase & & - & & & & \\
\hline AN4372 & pgaB, polygalacturonase ${ }^{a}$ & & & & - & - & - \\
\hline AN6470 & Putative N,O-diacetyl muramidase ${ }^{a}$ & & & & & & - \\
\hline AN7158 & Putative xylanase & & & & - & - & - \\
\hline AN7541 & Putative cutinase & - & - & & & - & - \\
\hline AN7891 & Putative GH family 61, extracellular & & - & & - & - & - \\
\hline AN8969 & Muramidase $>$ peptidoglycan hydrolysis & & - & & & - & - \\
\hline AN9365 & $x \ln B$, endo-1,4-beta-xylanase ${ }^{a}$ & - & - & & & & \\
\hline AN2385 & Putative xgeA, Licheninase, GPI-anchored ${ }^{a}$ & & - & & & & \\
\hline AN3308 & amyD, Amylase & & - & & & & \\
\hline \multicolumn{8}{|c|}{ Asexual specific } \\
\hline AN3883 & Putative extracell. endo-1,3(4)-beta-glucanase & + & + & & & & \\
\hline AN5267 & faeC, ferulic acid esterase $\mathrm{a}^{\mathrm{a}}$ & + & + & & & & \\
\hline AN7180 & Cutinase $^{a}$ & & + & & & & \\
\hline \multicolumn{8}{|c|}{ Sexual specific } \\
\hline AN0543 & Lysine dom. bacterial cell wall degradation & & & & & & + \\
\hline AN0711 & Putative alpha-L-rhamnosidase & & & + & & & \\
\hline AN1477 & beta-1,4-xylosidase, GH43 & & & & & & + \\
\hline AN2569 & Putative pectin lyase & & & + & & & \\
\hline AN5320 & Endoglucanase E-like & & & & & & + \\
\hline AN8453 & Putative pectin lyase & & & + & & & \\
\hline AN8466 & Lysine dom. protein, bacterial cell-wall & & & & & + & + \\
\hline AN8891 & Exopolygalacturonase & & & & + & & + \\
\hline \multicolumn{8}{|c|}{ Asexually and sexually expressed } \\
\hline AN0245 & Putative extracellular endo-1,3(4)-beta-glucanase GH 16 & + & + & & & + & \\
\hline AN5282 & cbhC, 1,4-beta-cellobiosidase ${ }^{a}$ & & + & & & + & + \\
\hline AN5309 & Cutinase & + & + & & & & + \\
\hline AN6518 & Putative endoxylanase & + & + & & + & + & + \\
\hline AN7828 & Unsaturated rhamnogalacturonan hydrolase, GH 88 & + & + & & & + & + \\
\hline AN8007 & $a b n C$, endo-1,5-alpha-t-arabinosidase ${ }^{\mathrm{a}}$ & + & + & & + & + & + \\
\hline AN8890 & Cellobiose dehydrogenase & + & + & & & + & + \\
\hline AN9383 & Unsaturated rhamnogalacturonan hydrolase, GH 88 & & + & + & + & + & \\
\hline AN11143 & gla $A$, glucoamylase & & + & & & + & + \\
\hline AN3402 & $a m y B$, Amylase $^{a}$ & + & + & & + & + & + \\
\hline
\end{tabular}

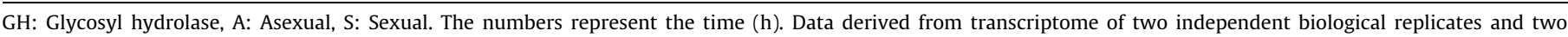
microarray platforms. Cut off was set to $\log 2 \geqslant \pm 1.5$.

a Indicates validated genes by other studies.

Table 2

Light-specific genes important for development, programmed cell-death and oxidative stress response trigger reactive oxygen levels in A. nidulans.

\begin{tabular}{|c|c|c|c|c|c|c|c|}
\hline Gene ID & Function & A24 & A48 & S24 & S48 & S72 & S96 \\
\hline \multicolumn{8}{|c|}{ Asexual specific apoptosis } \\
\hline AN9315 & $\begin{array}{l}\text { Yeast apoptosis initiation } \\
\text { factor } 1 \text { (AIF1) homolog }\end{array}$ & + & & & & & \\
\hline AN4874 & $\begin{array}{l}\text { Yeast ortholog } R N Y 1 \\
\text { promotes apoptosis }\end{array}$ & & + & & & & \\
\hline \multicolumn{8}{|c|}{ NADPH oxidases (Nox) } \\
\hline AN0773 & Nox uncharacterized & & & - & & & - \\
\hline AN10893 & Nox uncharacterized & & - & & & - & - \\
\hline AN4906 & Nox uncharacterized & & & & & + & \\
\hline AN8683 & Nox uncharacterized & & & & & + & \\
\hline \multicolumn{8}{|c|}{ Superoxide dismutases (SOD) } \\
\hline AN5148 & Uncharacterized Fe-SOD & & & & & & - \\
\hline AN0785 & SodM $^{\mathrm{a}}$ & & & & + & & \\
\hline \multicolumn{8}{|c|}{ Catalase and peroxidases } \\
\hline AN7388 & cpeA, catalase peroxidase ${ }^{a}$ & + & + & & + & + & \\
\hline AN8637 & $\begin{array}{l}\text { cat } A, \text { conidia specific }_{\text {catalase }^{a}}\end{array}$ & + & + & & & & \\
\hline AN9339 & catB, hyphal catalase $\mathrm{a}^{\mathrm{a}}$ & & - & & & & \\
\hline AN8553 & Uncharacterized catalase & + & + & & & & \\
\hline
\end{tabular}

a Indicates validated genes by other studies. induction in darkness. One of four genes, coding for a prenyltransferase ( $x p t A$, AN6784) involved in emericellin and shamixanthone synthesis was also found to be expressed at S72. Another S72 specific gene encodes a dimethylallyl tryptophan synthase (DMATS) aromatic prenyltransferase (AN11080). Members of this protein family were mostly fungal enzymes involved in secondary metabolite and toxin biosynthesis. Two genes encoding clavaminic acid synthetase (CAS)-like proteins were specifically expressed at S72. CAS is a trifunctional Fe(II)/2-oxoglutarate (2OG) oxygenase that was described to produce clavaminic acid, an inhibitor of beta-lactamases in bacteria. The biological function of both genes is still unknown in A. nidulans but implies a possible role in enhancing the effect of penicillin, directed to beta-lactamase producing bacteria. Additionally, expression of the aptA gene encoding the polyketide synthase (PKS) (AN6000) within the asperthecin (apt) gene cluster was restricted to the sexual development. This PKS was crucial for the synthesis of asperthecin as it was described for deletion of aptB (AN6001) and aptC (AN6002) (Szewczyk et al., 2008). Both aptB and aptC genes belong to the apt gene cluster and were upregulated at $\$ 96$ additionally.

Besides the previously given examples from the secondary metabolism category, top 20 of stage specific expressed genes were 
selected and listed in Table 3. Among A24 specifically expressed genes there were two genes for a putative chromosome segregating ATPase (AN10385) and a heterokaryon incompatibility protein (HET, AN3554). The AN3079 encodes thaumatin-like protein CetA that was shown to have a role in early conidiation and was expressed at A48 specifically (Bernstein et al., 2005). Protein degradation might affect proteins from several categories like development, secondary metabolism, cell cycle control, signal transduction and many other pathways. The protein quality control HRD ubiquitin ligase AN7294, which labels substrates for endoplasmatic reticulum associated protein degradation, was specifically upregulated at the A48 point of time.

A salicylate 1-monooxygenase (salA, AN3382) which is presumably involved in the resistance to the antifungal terbinafine, was only expressed at A48. S24 stage witnesses the least changes in gene expression. However, the genes for protein degradation and modification were the most interesting ones specifically expressed at this stage. Interestingly, putative F-box gene (AN0460) and three histone N-acetyltransferases ngn17 (AN0969), AN5330 and ngn28 (AN6411) were specifically expressed at S24. Furthermore, a putative phenazine biosynthesis-like protein required for the synthesis of the antibiotic phenazine (AN7010) was even activated at S24. lccC (AN5397) codes for an extracellular laccase, which oxidizes phenolic compounds. Together with the phenol 2monooxygenase (AN7418) A. nidulans seems to prepare for intraand extracellular detoxification towards toxic phenolic compounds at mid sexual stage $\mathrm{S} 48$.

Another putative F-box protein (AN0307) as well as a cAMPmediated signaling protein (AN10558) which is crucial for cellcycle progress were activated during late sexual stage S72. matB (AN2755) encoding an alpha-domain mating-type protein that regulates sexual development also specifically appeared at S72. In contrast, at S72 the fungus even activated $\operatorname{devR}$ (AN7553), which codes for an HLH transcription factor required for conidiophore formation and sexual development (Tuncher et al., 2004). This observation implies that $A$. nidulans induces conidiation even at sexual stage systematically. A putative NADPH oxidase (AN8683) was also expressed at S72.

Genes involved in protein degradation were also upregulated at very late sexual development S96. E2 ubiquitin conjugating enzyme (AN0482), which transfers the ubiquitin to proteins to be degraded, was specifically expressed at S96. Arrestin, the Nterminal domain protein (AN5453) associated with the ubiquitin ligase Rsp5 and a putative interferon-related developmental regulator (IFRD, AN10141) were also activated at S96. A protein involved in cell aging (thiA, AN10492), which is a sensor of mitochondrial dysfunction, was upregulated at S96. These alterations in gene expression suggest that in contrast to the delayed initial latent phase without significant changes in dark (S48), early asexual (A24), late asexual (A48) as well as late sexual (S72, S96) stages lead to most drastic expressional changes where a variety of gene groups involved in signaling, reprogramming, protein degradation and SM were specifically expressed.

\subsubsection{Expression of light-induced genes is delayed in darkness during development}

Numerous genes, which were expressed in response to illumination (A24, A48), were not silenced in darkness but appeared with a delay at later sexual stages (S72, S96) (Supplementary data 6). This also correlates with a delayed formation of asexual spores in darkness in comparison to light. For a more detailed analysis, the two asexually induced cultures under light (A24, A48) were compared to dark-kept cultures (S24, S48, S72 and S96) (Fig. 5). Particularly, the comparison of the asexual condition A24 vs sexual development S24, S48 and S72 revealed a dynamic increase of upregulated genes with a delay in sexual stages in comparison to
Table 3

Top 20 of stage specific genes in asexual or sexual development of $A$. nidulans.

\begin{tabular}{|c|c|}
\hline Gene ID & Function \\
\hline \multicolumn{2}{|c|}{ A24 specifically expressed } \\
\hline AN10385 & Putative chromosome segregation ATPase \\
\hline AN3554 & Putative heterokaryon incompatibility protein (HET) \\
\hline \multicolumn{2}{|c|}{ A48 specifically expressed } \\
\hline AN3079 & $\begin{array}{l}\text { cet } A \text {, secreted thaumatin-like protein with role in early } \\
\text { conidiation }^{\text {a }}\end{array}$ \\
\hline AN3382 & $\begin{array}{l}\text { salA, salicylate } 1 \text {-monooxygenase confers resistance to antifungal } \\
\text { terbinafine }^{a}\end{array}$ \\
\hline AN7294 & $\begin{array}{l}\text { Putative PHD and RING finger domain protein (HRD ubiquitin } \\
\text { ligase complex) }\end{array}$ \\
\hline \multicolumn{2}{|c|}{ S24 specifically expressed } \\
\hline AN0460 & Putative F-box protein \& WD40 domain \\
\hline AN0969 & $\begin{array}{l}\text { ngn } 17 \text {, uncharacterized GNAT family N-acetyltransferase (Histone } \\
\text { modification) }\end{array}$ \\
\hline AN5330 & GNAT family N-acetyltransferase \\
\hline AN6411 & $\begin{array}{l}\text { ngn } 28 \text {, uncharacterized GNAT family N-acetyltransferase (Histone } \\
\text { modification) }\end{array}$ \\
\hline AN7010 & $\begin{array}{l}\text { Phenazine biosynthesis-like protein (putative antibiotic } \\
\text { biosynthesis) }\end{array}$ \\
\hline \multicolumn{2}{|c|}{ S48 specifically expressed } \\
\hline AN5397 & lccC, extracellular laccase $e^{a}$ \\
\hline AN7418 & Putative phenol 2-monooxygenase (detoxification) \\
\hline \multicolumn{2}{|c|}{ S72 specifically expressed } \\
\hline AN0307 & Putative F-box protein \\
\hline AN10558 & cAMP-mediated signaling protein, putative (cell cycle progress) \\
\hline AN2755 & $\begin{array}{l}\text { mat } B, \alpha \text {-domain mating-type protein regulating sexual } \\
\text { development }^{\mathrm{a}}\end{array}$ \\
\hline AN7553 & $\begin{array}{l}\text { devR, HLH transcription factor required for conidiophore } \\
\text { development }^{\mathrm{a}}\end{array}$ \\
\hline AN8683 & Puative NADPH oxidase (NOX) \\
\hline \multicolumn{2}{|c|}{ S96 specifically expressed } \\
\hline AN0482 & Putative E2 ubiquitin conjugating enzyme \\
\hline AN10141 & Putative Interferone-related developmental regulator (IFRD) \\
\hline AN5453 & $\begin{array}{l}\text { Putative Arrestin, N-terminal domain protein (ubiquitin ligase } \\
\text { Rsp5 associated) }\end{array}$ \\
\hline
\end{tabular}

a Indicates validated genes by other studies.

the A24 light response (Fig. 5A). Whereas A24 and S24 shared 32 up- and 50 downregulated genes (see also Fig. 3A), A24 and S72 exhibited 268 up- and 132 downregulated overlapping genes. In contrast, the number of upregulated overlapping genes between A48 and S48/S72/S96 remained mostly similar (Fig. 5B). The number of downregulated genes decreased from S48 to S96.

Increased expression of $A$. nidulans genes with a delay in dark can be found for specific functional gene categories when A24 vs. S48 and A24 vs. S72 are compared. Genes from primary metabolism, transport, transcription, signal transduction and development categories indicated highest increase between A24 and S48, suggesting the requirement of the gene expression from these categories with only $24 \mathrm{~h}$ delay as preparation for another round of development. Activation of genes from primary metabolism assures a stable energy supply together with upregulation of transport genes that stimulates uptake of essential nutrients from extracellular environment for direct usage. There is a second group of genes that show a different delay period. The number of upregulated SM genes increased from 5 (A24 vs. S48) to 38 genes (A24 vs. S72) (Fig. 5C). Similarly, genes for cell wall remodeling and degradation increased from 3 (A24 vs. S48) to 15 genes (A24 vs. S72), demonstrating a different $48 \mathrm{~h}$ delay in expression of these genes.

The overall number of delayed genes remained the same or even decreased when A48 vs S48/S72/S96 were compared. For instance, 18 (A48 vs. S72) and 19 (A48 vs. S96) primary metabolism genes were upregulated respectively. The number of upregulated secondary metabolism genes even decreased from 28 (A48 
A

A24

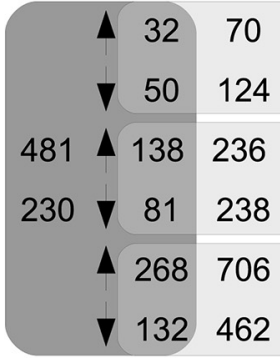

S24

S48

S72
B

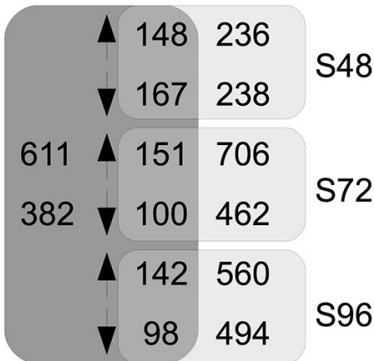

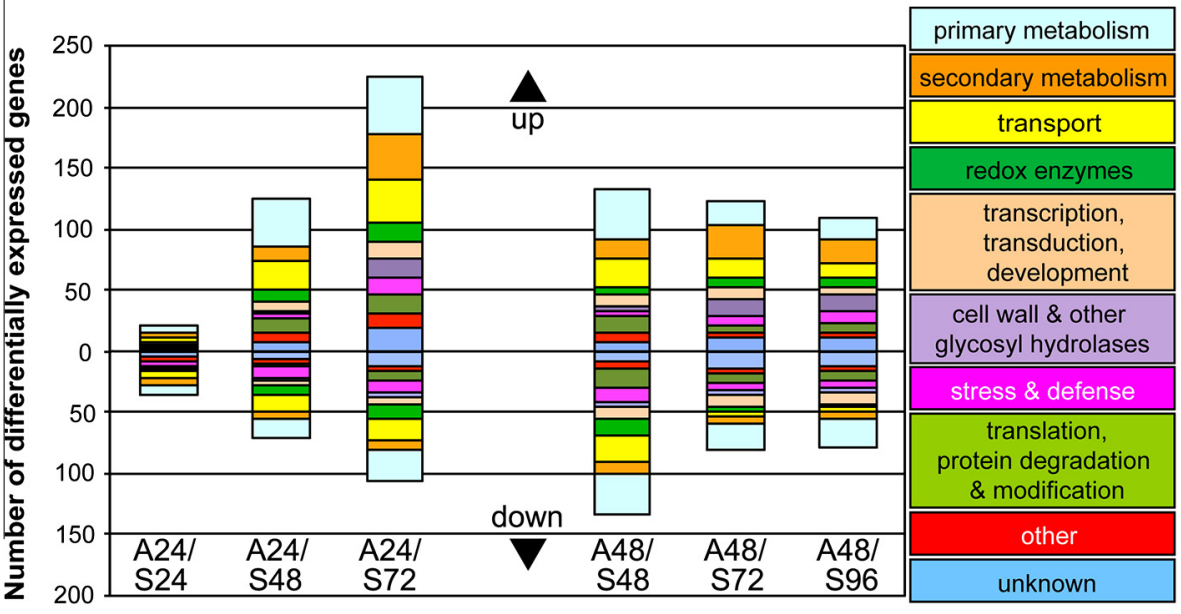

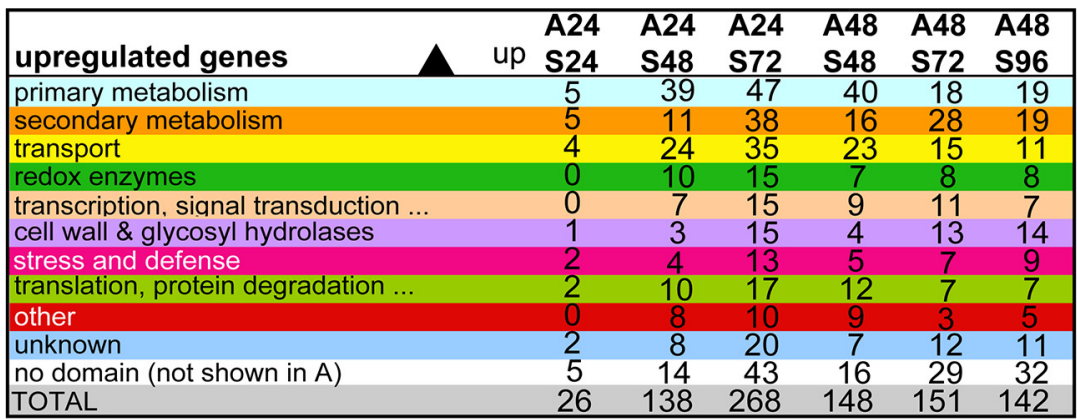

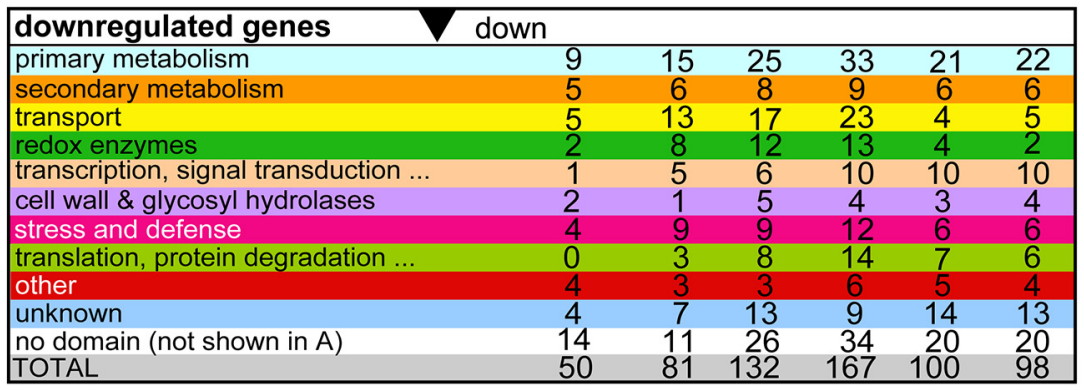

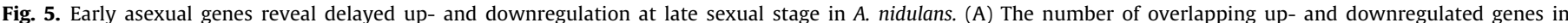

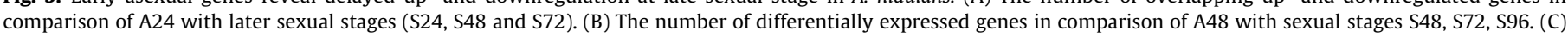

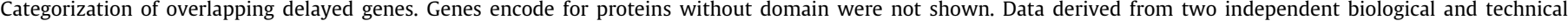
replicates performed on two different microarray platforms (TIGR and AGILENT). Cut off is at $\log 2 \geqslant \pm 1.5$.

vs. S72) to 19 (A48 vs. S96). The number of upregulated genes showed consistency. Among the delayed genes derived from different categories, the top 20 genes of SM, transcription, signal transduction, development, cell-wall remodeling, glycosyl hydrolyzation, protein degradation and modification were depicted and listed in Table 4 . Within the secondary metabolite category there were four interesting delayed candidates, a putative bioluminescence LuxE-like acyl-protein synthetase (AN4201), a putative tyrosinase (AN8435) expressed at A48 and with $24 \mathrm{~h}$ delay at S72, dopa-4,5-dioxygenase (AN4806) that produces betalamic acid (betalain), a yellow chromophore also present in basidiomycetes. Fourth candidate was AN8134, homolog to an anthranilate N-hydroxycinnamoyl/benzoyltransferase that presumably catalyzes phytoalexin biosynthesis in plants. Phytoalexins of the plants are first defense mechanisms on bacterial or fungal infections (Schmelz et al., 2014). AN8134 expression started at vegetative stage and was still present at $\mathrm{S48}$, which might also possess a similar function in $A$. nidulans. 
Many of the listed candidates belong to transcription-signal transduction-development category since they might play important roles in developmental reprogramming. AN10600, a fungal-specific $\mathrm{Zn}(\mathrm{II}) 2 \mathrm{Cys} 6$ transcription factor with potential for initiation of asexual differentiation and conidiophore formation, was present at both asexual stages and solely expressed at S72. RNA silencing represents another posttranscriptional control of gene expression. Argonaute encoding gene (AN1519) was expressed during asexual and sexual development with $24 \mathrm{~h}$ delay. It was already activated at early asexual stages whereas it appeared at S72. Either it is passively involved in the activation of sexual development or it de-represses asexual differentiation. An aegerolysin-like protein (AN1553) was expressed at early asexual stage and at sexual development with $24 \mathrm{~h}$ delay. Aegerolysin and ostreolysin are produced during formation of primordia and fruiting body in fungi. A putative RNase was upregulated at A24 and S48. In eukaryotes RNaseIII or RNaseIII-like enzymes such as Dicer are involved in RNAi and miRNA gene silencing. As differentially expressed argonaute (AN1519), RNAase III was an additional factor for post-transcriptional control and might have an important impact on A. nidulans development. Phospholipases are part of signal cascades in pro- and eukaryotic organisms. A putative phospholipase (AN6382) was also expressed at S72 and S96. The catalase-peroxidase cpeA (AN7388) had been identified as laccase II expressed during sexual development (Scherer and Fischer, 1998; Scherer et al., 2002). We found cpeA was also expressed at both asexual stages and with $24 \mathrm{~h}$ delay at sexual stages S48 and S72. Heterokaryon incompatibility protein (HET, AN8923) is restricted to ascomycetes and differences in HET genes prevent a viable heterokaryotic fungal cell formation by the fusion of two different wild types. The HET gene was already activated at early asexual stage and was merely present at S72. tmpA (AN0055), a transmembrane flavoprotein involved in conidiophore formation (Soid-Raggi et al., 2006) was expressed at vegetative stage and present until A24 and at S72 with 48 delay. The oleate delta-12 desaturase, odeA (AN1037) was also expressed at vegetative stage and its expression still existed at A24 and S48. Since odeA participates in conidiation and is expressed in sexual stage with 24 h delay, it might control delayed conidiation at sexual differentiation in $A$. nidulans. Cyclin box fold (AN10741) expression already started at vegetative growth and was still present at early sexual stage S24. The putative NADPH oxidase (AN10893) first expressed at vegetative growth, its expression remained stable until A24 and S48. Like NoxA, this uncharacterized Nox might also control and regulate A. nidulans development through triggered ROS generation. Expression of a putative extracellular serine-rich protein (AN3310) was restricted to vegetative stage and S24. Conidiation proteins are specific for asexual differentiation. Conidiation specific gene cffA (AN5844) (Suzuki et al., 2013) was also activated at S24 and S48 with 24 h delay representing strong evidence for a delayed initiation of asexual differentiation at sexual development. Beside its expression at vegetative stage the zinc-dependent metalloprotease (AN8132) expression was still detectable at S24. It has wide phylogenetic distribution and contains sub-families involved in vertebrate development and might be also required for initiation of sexual development. ChiB (AN4871) a chitinase class V crucial for autolysis and aging in A. nidulans was already expressed at A24, whereas it was merely activated at S72 when sexual development was at an advanced stage. The putative F-box protein (AN6625) was expressed at A24 and S48 exhibited a 24 h delay.

Depending on the point of view, these expression data suggest that there is a delay in gene expression during sexual development in comparison to asexual development or an enhancement of gene expression as a consequence of light. This delay stems from the idle expression phase during first 24 or $48 \mathrm{~h}$ of sexual development in darkness, which can be suppressed by light. The delay of
Table 4

Top 20 of delayed genes expressed comparing asexual and sexual development of $A$. nidulans.

\begin{tabular}{|c|c|c|c|c|c|c|c|}
\hline Gene ID & Function & A24 & A48 & S24 & S48 & S72 & S96 \\
\hline \multicolumn{8}{|c|}{ Secondary metabolism } \\
\hline AN4201 & $\begin{array}{l}\text { Acyl-protein synthetase, } \\
\text { LuxE }\end{array}$ & + & & & + & + & \\
\hline AN8435 & $\begin{array}{l}\text { Putative tyrosinase } \\
\text { (pigment formation) }\end{array}$ & & + & & & + & + \\
\hline AN4806 & $\begin{array}{l}\text { Putative dopa } 4,5- \\
\text { dioxygenase (betalain) }\end{array}$ & & - & & & - & - \\
\hline AN8134 & $\begin{array}{l}\text { Putative transferase } \\
\text { family (phytoalexine) }\end{array}$ & - & - & & & - & - \\
\hline \multicolumn{8}{|c|}{ Transcription, signal transduction, development } \\
\hline AN10600 & $\begin{array}{l}\text { Putative } \mathrm{Zn}(\mathrm{II})_{2} \mathrm{Cys}_{6} \\
\text { transcription factor }\end{array}$ & + & + & & & + & \\
\hline AN1519 & $\begin{array}{l}\text { Putative Argonaute } \\
\text { protein (RNA silencing) }\end{array}$ & + & + & & & + & + \\
\hline AN1553 & $\begin{array}{l}\text { Putative Aegerolysin-like } \\
\text { protein }\end{array}$ & + & + & & + & + & \\
\hline AN5408 & $\begin{array}{l}\text { Putative RNAse III (RNAi } \\
\text { silencing) }\end{array}$ & + & & & + & & \\
\hline AN6382 & $\begin{array}{l}\text { Putative Phospholipase C } \\
\text { (signal cascade) }\end{array}$ & & + & & & + & + \\
\hline AN7388 & $\begin{array}{l}\text { cpeA, catalase- } \\
\text { peroxidase }^{\mathrm{a}}\end{array}$ & + & + & & + & + & \\
\hline AN8923 & $\begin{array}{l}\text { Putative heterokaryon } \\
\text { incompatibilty protein }\end{array}$ & + & + & & & + & + \\
\hline AN0055 & $\begin{array}{l}\text { tmpA, involved in } \\
\text { regulation of conidiation }\end{array}$ & & - & & & & - \\
\hline AN1037 & $\begin{array}{l}\text { odeA, oleate delta-12 } \\
\text { desaturase }^{\text {a }}\end{array}$ & & - & & & - & - \\
\hline AN10741 & $\begin{array}{l}\text { Cyclin box fold for } \\
\text { transcriptional control }\end{array}$ & - & - & & - & - & - \\
\hline AN10893 & Putative NADPH oxidase & & - & & & - & - \\
\hline AN3310 & $\begin{array}{l}\text { Putative Extracellular } \\
\text { serine-rich protein }\end{array}$ & - & - & & - & - & - \\
\hline AN5844 & $c f f A$ (conidiation protein) ${ }^{a}$ & & - & & & - & - \\
\hline AN8132 & $\begin{array}{l}\text { Zinc-dependent } \\
\text { metalloprotease }\end{array}$ & - & - & & - & - & - \\
\hline \multicolumn{8}{|c|}{ Cell wall remodeling and glycosyl hydrolysis } \\
\hline AN4871 & $\begin{array}{l}\text { chiB, Chitinase class } \mathrm{V}^{\mathrm{a}} \\
\text { (autolysis \& aging) }\end{array}$ & + & + & & & + & + \\
\hline \multicolumn{8}{|c|}{ Protein degradation and modification } \\
\hline AN6625 & Putative F-box protein & + & & & + & + & + \\
\hline
\end{tabular}

a Indicates validated genes by other studies.

differential gene expression in darkness in comparison to light might be necessary to promote regulatory genes involved in enhanced reprogramming the fungus for sexual development.

3.3.3. Completion of development coincides with reduced formation of amino acids as precursors of translation and increases secondary metabolism

Amino acids are the monomers for the protein biosynthesis and have a function as building blocks in secondary metabolite formation such as nonribosomal peptide synthesis (NRPS). By the metabolite fingerprinting approach the intracellular content of 13 amino acids of $A$. nidulans could be described resulting in a very heterogenous intensity pattern during development (Table 5).

Methionine accumulates at S24 specifically. Methionine and its derivative S-adenosyl methionine (SAM) serve as methyl donors. The levels of the alanine, glutamate and aspartate group were negligible at both late developmental stages. Both alanine and glutamate were present at vegetative stage whereas alanine was also detectable at early sexual stage S24 and glutamate at early asexual stage A24 specifically. Alanine can be part of some peptide antibiotics, which might be specific for vegetative growth and early sexual stage S24. Threonine accumulation was highest at vegetative growth and both early development stages A24 and S24. Lysine 
accumulation is restricted to both early development stages A24 and S24 as well as to S48.

Phenylalanine is the starting compound used in flavonoid biosynthesis and of the pigment melanin as well. Melanin protects fungal tissues from UV damage. Phenylalanine was present at all analyzed stages and might be indispensable for $A$. nidulans with higher accumulation at A24 and all sexual stages. Asparagine accumulated at both $24 \mathrm{~h}$ and $48 \mathrm{~h}$ stages of sexual and asexual differentiation. As a non-proteinogenic amino acid, ornithine is the starting compound of polyamine synthesis. Polyamines are involved in signaling, important for growth and differentiation in numerous organisms. A. nidulans might control growth of its prokaryotic competitors in soil since the polyamine putrescine in large doses is toxic, which induces apoptosis. Polyamine shows enhanced level at vegetative and early sexual stage.

Histidine contains imidazole group involved in oxidative stress responses. On the one hand histidine is a precursor in carnosine biosynthesis, which has been proven to scavenge reactive oxygen species (ROS). Furthermore, in Actinomycetes or filamentous fungi like A. fumigatu and $N$. crassa, histidine is converted into the antioxidant ergothioneine (Fahey, 2001; Gallagher et al., 2012). Histidine also participates in detoxification of excessive ROS from Nox activities during developmental induction. Histidine accumulated at asexual (A24 and A48) and mid-sexual development (S48, S72). The identity of lysine, aspartate, glutamate and glutamine, valine, methionine, ornithine, phenylalanine, proline and threonine were unequivocally confirmed by MS/MS fragmentation experiments with LC/ESI-QTOF-MS (Supplementary data 2).

Transcriptome analysis reveals massive downregulation of numerous genes at S96 (Table 6). Specifically, numerous amino acid biosynthesis genes were downregulated at S72 and S96. Amino acids were sorted into specific groups based on their common metabolism. One prominent group was the alanine, aspartate and glutamate group (Table 6). 11 genes involved in metabolism of these amino acids were differentially expressed. A broad downregulation of amino acid genes had a direct impact on amino acid homeostasis in A. nidulans. Genes required for protein translation exhibited diminished expression at the end of sexual development, which is in agreement with the observed downregulation of genes involved in amino acid metabolism (Supplementary data 1: Table S4). These translational genes contain a large group of proteins, including ribosomal large and small subunit components, initiation and elongation factors or tRNA synthetases. When $A$. nidulans cleistothecia were already mature and sexual development was completed at S96, 20 out of 33 differentially expressed translation genes showed specific downregulation.

These transcriptomic data suggest that the fungus requires certain types of amino acids at specific developmental stages, whereas amino acid biosynthesis and the translational machinery genes are simultaneously shut down by the end of sexual development. This is presumably part of a programmed cell-death where only the overwintering structures survive in soil and the conidia are released into the air.

\subsection{Light-versus dark: Metabolites}

\subsubsection{Development-specific metabolite patterns in A. nidulans}

Production of secondary metabolites and the formation of developmental structures are highly coordinated processes in fungi (Bayram and Braus, 2012). We examined the changes, which occurred in metabolite accumulation during different stages of fungal development and during different illumination conditions. Intracellular and extracellular metabolome data of the developmental stages of $A$. nidulans were obtained by metabolite fingerprinting analysis using a UPLC ESI-TOF-MS approach. For a comprehensive description of the metabolome of $A$. nidulans seven
Table 5

Abundance of amino acids during development of $A$. nidulans.

\begin{tabular}{|c|c|c|c|c|c|c|c|}
\hline Amino acids & Veg & A24 & A48 & S24 & S48 & S72 & S96 \\
\hline D-Met & & & & + & & & \\
\hline L-Ala & + & & & + & & & \\
\hline L-Glu & + & + & & & & & \\
\hline L-Asp & & + & & & + & + & \\
\hline $\mathrm{L}-\mathrm{G} \ln$ & & + & & & + & + & \\
\hline L-Thr & + & + & & + & & & \\
\hline L-Val & & & + & & & & \\
\hline L-Lys & & + & & + & + & & \\
\hline L-Phe & + & + & + & + & + & + & + \\
\hline L-Asn & & + & + & + & + & & \\
\hline L-Orn & + & & & + & & & \\
\hline L-Pro & & + & & + & + & & \\
\hline L-His & & + & & & + & + & \\
\hline
\end{tabular}

stages of development (Veg, A24, A48, S24, S48, S72, S96) of the intracellular metabolome (mycelium) as well as three stages (Veg, A48, S96) of the extracellular metabolome (culture supernatant) were analyzed and compared. Data preprocessing and data analysis led to a subset of 3162 high quality features (pVal $<1 \times 10^{-6}$, Supplementary data 3 ) for the intracellular metabolome and 3482 high quality features ( $\mathrm{pVal}<5 \times 10^{-3}$, Supplementary data 4 ) for the extracellular metabolome, respectively. The intensity profiles of all selected features were clustered by training a one-dimensional self-organizing map (1D-SOM) model for similarities in metabolite intensity patterns (Fig. 6A). The average of all intensity profiles combined by one cluster is represented by a prototype. 25 prototypes were chosen to represent the data of the intracellular metabolome and 10 for the representation of the extracellular metabolome. Data mining by means of $1 \mathrm{D}-\mathrm{SOMs}$ allows a global overview of all metabolite intensity patterns during development.

Data of intra- as well as extracellular metabolome showed blocks of comparable patterns (colored frames in Fig. 6A). The framed blocks represent features specific for the vegetative (orange labeled), the asexual (green labeled) or the sexual developmental stages (red labeled). The metabolome data showed a large block of shared features, which were enriched in the asexual and the sexual stage, except the early sexual stage S24 (cluster 15-18 for intracellular and cluster 6, 8, 9 for extracellular metabolome). The early sexual stage A24 showed rather similarities to the vegetative stage (Veg). The strong analogy between vegetative and early sexual stage (S24) on metabolite level became also apparent for cluster 2. Metabolite markers, specific for the vegetative growth were still present at the S24 stage. A remarkable profile was also shown by cluster 7 of the intracellular metabolome data. This prototype represents features, which exclusively occurred during the early sexual stage (S24). They could represent metabolites, which may operate as signal molecules for reprogramming the fungal metabolism.

The metabolome data support that the lipid composition of vegetative and early sexual development (S24) stage is very similar (Fig. 6B). Diacylglycerophosphocholines and diacylglyceropho sphoethanolamines (tentatively identified by exact mass, Supplementary data 3 ) were specifically enriched during both vegetative and S24 stages. Both lipid classes represent essential compounds of membranes. The lysophosphatidylethanolamine (LysoPE) species LysoPE16:0 (Supplementary data 2) was strongly enriched in both developmental stages. This molecular species induces a positive membrane curvature and thus may suggest an increased occurrence of vesicular transport (Brownell et al., 1996). 
Table 6

Global downregulation in the expression of amino acid biosynthesis genes during late sexual development in A. nidulans.

\begin{tabular}{|c|c|c|c|c|c|c|c|}
\hline Gene ID & Function & A24 & A48 & S24 & S48 & S72 & S96 \\
\hline \multicolumn{8}{|c|}{ Cysteine and methionine biosynthesis } \\
\hline AN1222 & sas $A$, AdoMet synthetase ${ }^{a}$ & & - & & & & - \\
\hline AN2882 & Homoserine dehydrogenase $^{a}$ & & & & & - & - \\
\hline AN4793 & Putative Aspartate-semialdehyde dehydrogenase & & & & & - & - \\
\hline AN8057 & $c y s B$, Cysteine synthase ${ }^{a}$ & & & & & - & - \\
\hline AN8277 & cys $D$, Homocysteine synthase ${ }^{a}$ & & & & & - & - \\
\hline \multicolumn{8}{|c|}{ Alanine, aspartate and glutamate biosynthesis } \\
\hline AN1883 & $\arg 3$, Argininosuccinate synthase ${ }^{a}$ & & & & & - & - \\
\hline AN1891 & Putative L-asparaginase & & + & & & & \\
\hline AN1923 & Alanine transaminase $\mathrm{e}^{\mathrm{a}}$ & & - & & & - & - \\
\hline AN2243 & Putative cpa, Carbamoyl-phosphate synthase & & & & & & - \\
\hline AN2914 & $\arg 1$, Argininosuccinate lyase ${ }^{\mathrm{a}}$ & & & & & - & - \\
\hline AN4159 & glnA, Glutamine synthetase a & & & & - & & - \\
\hline AN4376 & gdhA, NADP-specific glutamate dehydrogenase ${ }^{a}$ & & - & & - & - & - \\
\hline AN4401 & Asparagine synthase (glutamine-hydrolyzing), put & & & & & - & - \\
\hline AN5134 & gltA, Glutamate synthase ${ }^{\mathrm{a}}$ & & & - & - & & - \\
\hline AN5447 & Putative Glutamate decarboxylase & - & - & & - & - & - \\
\hline AN7451 & gdhB, Glutamate dehydrogenase ${ }^{a}$ & + & + & & & + & + \\
\hline \multicolumn{8}{|c|}{ Glycine, threonine and serine biosynthesis } \\
\hline AN2284 & hemA, 5-aminolevulinic acid synthase, mitochondrial precursor, put. & & - & & - & - & - \\
\hline AN2532 & Putative Primary-copper amine oxidase 1 & & & - & & & \\
\hline AN2882 & Homoserine dehydrogenase $^{a}$ & & & & & - & - \\
\hline AN3031 & Putative Threonine synthase & & & & & - & - \\
\hline AN3291 & Putative Monoamine oxidase & & & & & + & \\
\hline AN4793 & Putative Aspartate-semialdehyde dehydrogenase & & & & & - & - \\
\hline AN5444 & Putative D-3-phosphoglycerate dehydrogenase & & - & & & - & - \\
\hline AN5690 & Putative Primary-amine oxidase & & & & + & & \\
\hline AN6943 & Putative Glycerate kinase & & + & & & & \\
\hline AN7641 & Putative Primary-amine oxidase & + & + & & + & + & + \\
\hline AN8843 & Putative Homoserine kinase & & & & & - & - \\
\hline AN8866 & Putative D-3-phosphoglycerate dehydrogenase & & & & & - & - \\
\hline \multicolumn{8}{|c|}{ Valine, leucin and isoleucin biosynthesis } \\
\hline AN0705 & Putative Isoleucyl-tRNA synthetase & & & & & & - \\
\hline AN0840 & Putative 2-isopropylmalate synthase & & - & & & - & - \\
\hline AN0912 & Putative 3-isopropylmalate dehydrogenase A & & & & & - & - \\
\hline AN2526 & Putative ketol-acid reductoisomerase & & & & & - & - \\
\hline AN4323 & Branched-chain amino acid aminotransferase & & - & & & - & - \\
\hline AN5162 & $p d h B$, pyruvate dehydrogenase E1 subunit alpha ${ }^{a}$ & & & & & & - \\
\hline AN6364 & sudA, Dihydroxy-acid dehydratase ${ }^{\mathrm{a}}$ & & & & & - & - \\
\hline AN9403 & pdhC, pyruvate dehydrogenase E1 subunit beta ${ }^{a}$ & & & & & & - \\
\hline \multicolumn{8}{|c|}{ Lysine biosynthesis } \\
\hline AN2882 & Homoserine dehydrogenase ${ }^{a}$ & & & & & - & - \\
\hline AN4793 & Putative Aspartate-semialdehyde dehydrogenase & & & & & - & - \\
\hline AN5206 & lys $B$, Homoisocitrate dehydrogenase $\mathrm{a}^{\mathrm{a}}$ & & & & & - & - \\
\hline AN5601 & Putative Saccharopine dehydrogenase & & & & & - & - \\
\hline AN6521 & lysF, Homoaconitase, mitochondrial precursor ${ }^{a}$ & & & & & & - \\
\hline \multicolumn{8}{|c|}{ Phenylalanine, tyrosine and tryptophan biosynthesis } \\
\hline AN1137 & $q u t B$, Quinate dehydrogenase ${ }^{a}$ & - & - & & & - & - \\
\hline AN5444 & Putative Tryptophan synthase beta chain & & - & & & - & - \\
\hline AN5731 & Chorismate synthase & & - & & - & - & - \\
\hline AN6403 & 3-Dehydroquinate synthase & + & + & & & & \\
\hline
\end{tabular}

a Indicates validated genes by other studies.

3.4.2. Development in A. nidulans reveals characteristic linoleic and oleic acid derived psi-factor ratios and dioxygenase expression

A. nidulans development is accompanied by the synthesis of characteristic linoleic and oleic acid derived psi-factors (lipid hormones) and development specific expression of the dioxygenases ppoA (AN1967) and ppoC (AN5028) catalyzing conversion of these psi-factors (Calvo et al., 2001; Champe and el-Zayat, 1989; Tsitsigiannis and Keller, 2006; Tsitsigiannis et al., 2004b). PpoA, which produces psiB1alpha (8-hydroxy-9(Z),12(Z)-octadecadienoic acid, 8-HOD) and psiB1ß (8-hydroxy-9(Z)-octadecenoic acid, 8$\mathrm{HOE}$ ), is required for sexual development. PpoC, which generates psiA1alpha (10-hydroxy-9(Z),12(Z)-octadecadienoic acid, 10HOD), is needed for asexual sporulation. psiB1alpha (8-HOD) and psic1alpha (5,8-dihydroxy-9(Z),12(Z)-octadecadienoic acid, 5,8DiHOD) are reported to stimulate sexual spore development whereas psiA1 $\alpha$ lactone ring of $p s i C$ at position 5) inhibits sexual spore development (Champe and el-Zayat, 1989). Deletion of ppoA leads to reduction of 8 -HOD and complete loss of 5,8-DiHOD biosynthesis, which resulted in a changed ratio of 8-HOE:8-HOD. This leads to more asexual structures in $\triangle p p o A$ deletion mutant strains. Expression of $p p o A$ was higher at vegetative growth, implying that the fungus seems to be already competent for sexual development at even vegetative stage (Fig. 7). ppoA expression was similar at both early stages of development (A24, S24) and increased gradually and reached its highest expression through S72 and S96. 8-HOE:8-HOD ratio was around 3-fold higher at A24 compared to S24 (9.4:1 vs. 3.2:1). At A48 the ratio was 10.8:1 compared to $3.1: 1$ at $S 48$, which were consistent with the observation described by Tsitsigiannis et al. (2004a, 2004b). At sexual development S72 and S96 8-HOE:8-HOD ratio reached to 

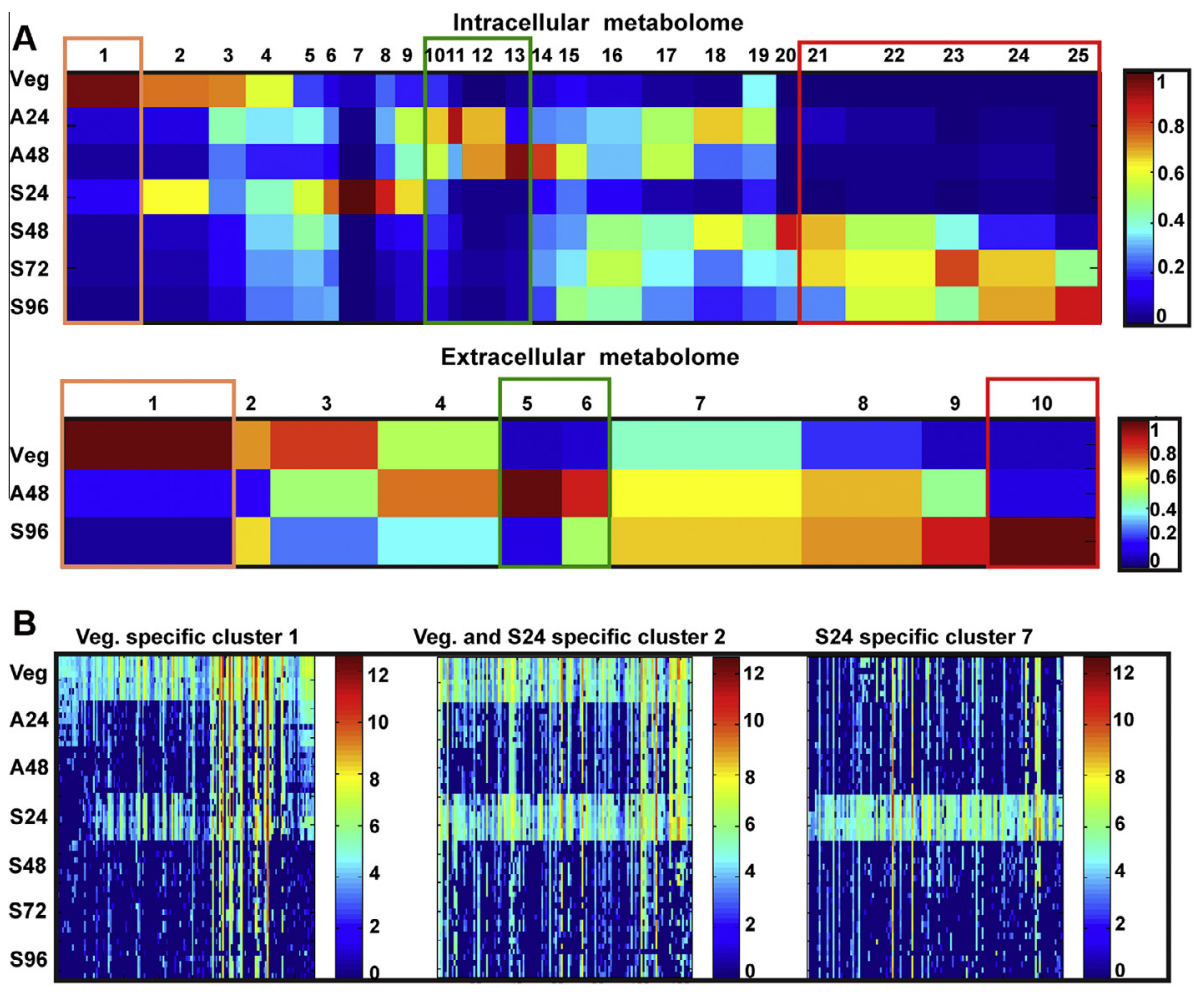

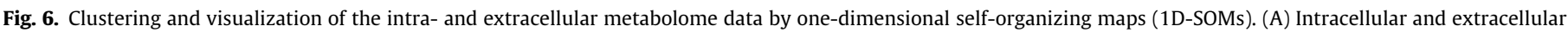

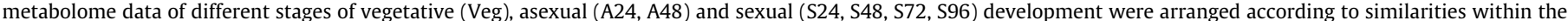

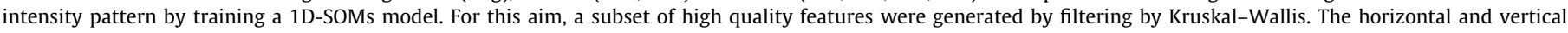

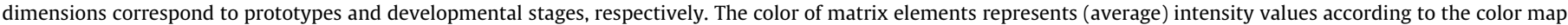

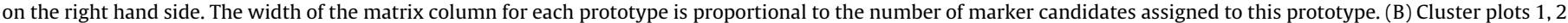
and 7 display intensity pattern of features specific for vegetative growth (Veg) and early sexual development (S24).

asexual level (10.3.1 and 13.4:1), which were consistent with secondarily formed asexual structures during sexual development. Deletion of $p p o C$ results in an increased number of ascospores and causes a reduction in racemic form of 10-HOD but did not affect the biosynthesis of other oxylipins (Garscha et al., 2007). ppoC expression was similar at vegetative and asexual stage, but showed a decrease during sexual development (Fig. 7C). However, in contrast to expression levels, product of this enzyme 10-HOD showed a peak at S24 when its expression level was at lowest level. 10-HOD levels dramatically dropped down from S24 to S48 and stayed at low levels through all sexual development. Thus, 10HOD presents a marker specific for early sexual development and might be required for a proper ratio of asexual to sexual spores in $A$. nidulans.

Hydroxylated derivatives of oleic acid ( $p \operatorname{siA1} \beta$ ( $p$ siC1 $\beta$ with lactone ring at C-5), psiB1 $\beta$ (8-HOE), and psiC1 $\beta$ (5,8-DiHOE)) have also been isolated from $A$. nidulans. Impact of oleic acid derived psi-factors on $A$. nidulans development is mostly unknown. Calvo et al. (2001) analyzed a desaturase odeA deletion strain and could show that this strain was depleted of polyunsaturated fatty acids (18:2 and 18:3) but increased in oleic acid (18:1). Development of the odeA mutant shifted to sexual direction. This data suggest that oleic acid derivatives have an effect on the ratio of asexual to sexual spores in A. nidulans. Our transcriptome data show that there is a co-expression pattern where beside the previously characterized desaturase gene odeA (AN1037), the an2 gene for another monofunctional desaturase (AN7204) was already expressed at vegetative growth and still present at early asexual (A24) and sexual (S24) development (Table 7). An2 was biochemically and structurally characterized but the effect of an an2 deletion on A. nidulans development has not been analyzed yet (Hoffmann et al., 2007). Interestingly an2 expression (Table 7) was already present at veg- etative growth when the fungus requires developmental competence to differentiate asexually or sexually. Even more interesting was the finding that the oleic acid derived 5,8-DiHOE was only specifically present in early sexual development S24 and its concentration decreased massively and was not detectable in late sexual development. Furthermore even 8-HOD:10-HOD ratio was development specific in A. nidulans. Ratio of 8-HOD to 10-HOD was almost similar at A24, A48, S24 and Veg (1.7:1-1:2.5), whereas it was altered from $1: 2.5$ at S24 to $4.6: 1$ at S96 in 8HOD direction, which was consistent with the findings of Garscha et al. (2007).

Preparation for psi-factor synthesis requires different initial steps starting from fatty acid beta-oxidation located in peroxisomes, long chain fatty acid synthesis and oleic acid and linoleic acid synthesis specifically. Initial fatty acid oxidation in A. nidulans is mediated through the peroxisomal multifunctional enzyme encoded by foxA (AN7111) (Maggio-Hall and Keller, 2004). foxA transcription increased at $\mathrm{S} 72$ specifically. In contrast, fas $A$ (AN9407) a fatty acid synthase was already expressed at vegetative growth and early sexual development S24 and S48 (Table 7). Deletion of fasA was described to be lethal for A. nidulans (Brown et al., 1996; David et al., 2008). The fasA gene is crucial for the fungal long chain fatty acids supply which is required for membrane formation during general cellular fungal growth and specifically for psi-factor formation. Palmitic- and stearic acids are among the long fatty acids. The putative delta-9-stearic acid desaturase SdeB (AN4135) converts both fatty acids to palmitoleic acid and oleic acid, the precursor of oleic acid derived psi-factors. As observed for fasA, the $s d e B$ gene encoding another stearic acid desaturase was also specifically expressed at vegetative growth and early sexual stage S24. A fasA $s d e B$ double deletion was lethal for $A$. nidulans emphasizing the importance of desaturases (Maggio-Hall and Keller, 2004). 

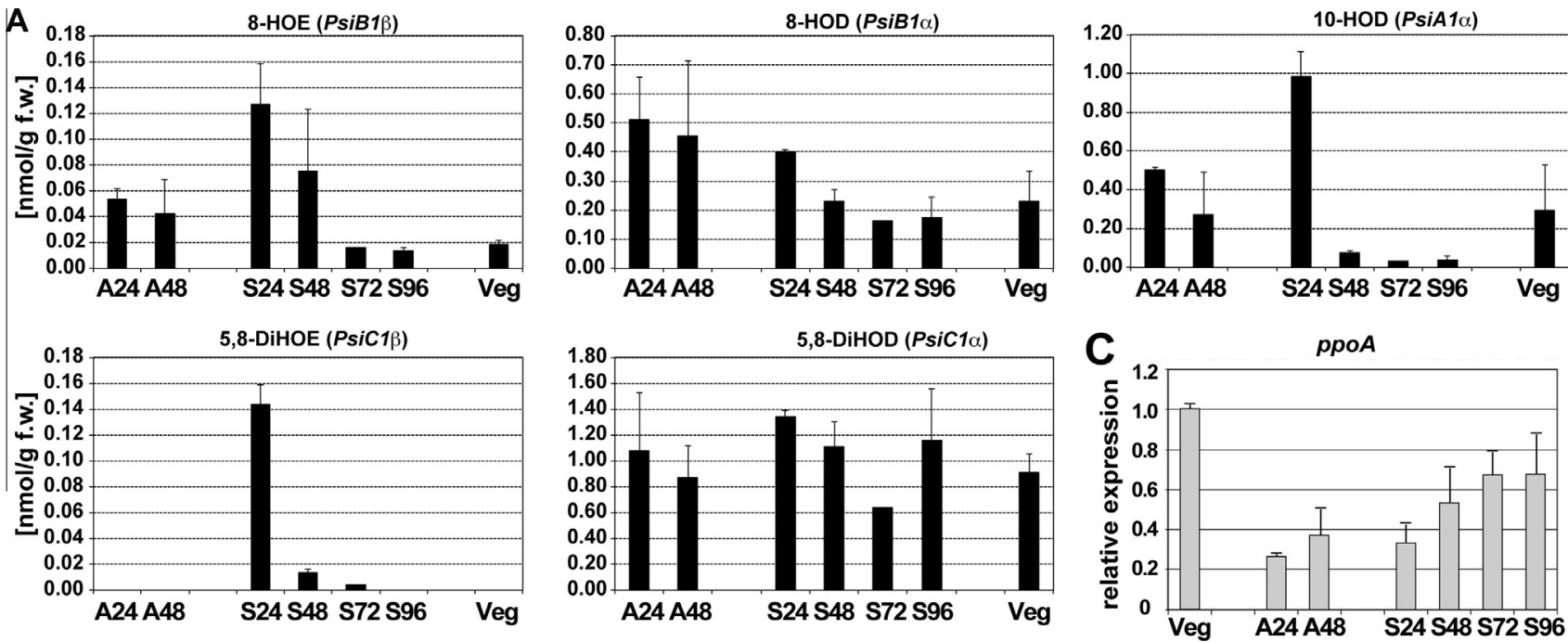

B

8-HOE:8-HOD 8-HOD:10-HOD 5,8-DiHOE:5,8-DiHOD

\begin{tabular}{cccc}
\hline A24 & $9,4: 1$ & $1: 1$ & only 5,8-DiHOD \\
A48 & $10,8: 1$ & $1,7: 1$ & only 5,8-DiHOD \\
\hline S24 & $\mathbf{3 , 2 : 1}$ & $\mathbf{1 : 2 , 5}$ & $\mathbf{1 : 9 , 3}$ \\
S48 & $\mathbf{3 , 1 : 1}$ & $3: 1$ & $1: 79,6$ \\
S72 & $10,3: 1$ & $4,6: 1$ & $1: 159,8$ \\
S96 & $13,4: 1$ & $4,4: 1$ & only 5,8-DiHOD \\
\hline Veg & $12,9: 1$ & $1: 1,3$ & only 5,8-DiHOD
\end{tabular}

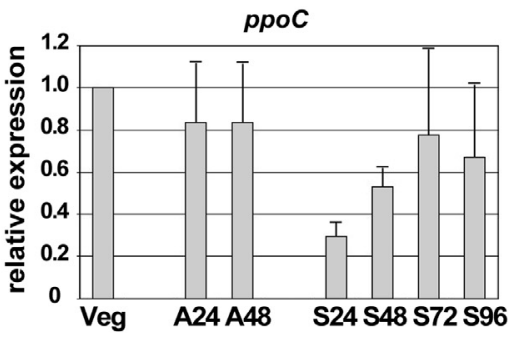

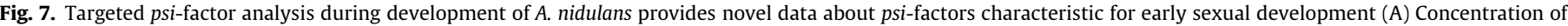

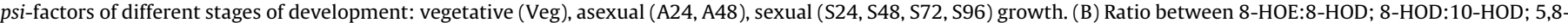

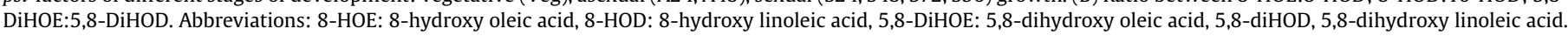

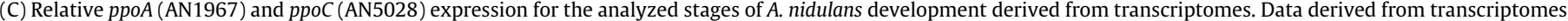
of two independent biological replicates and two microarray platforms. Cut off was set to $\log 2 \geqslant \pm 1.5$.

Table 7

Genes involved in linoleic- and oleic acid conversion and formation of polyunsaturated fatty acids expressed during $A$. nidulans development.

\begin{tabular}{|c|c|c|c|c|c|c|c|}
\hline Gene ID & Function & A24 & A48 & S24 & S48 & S72 & S96 \\
\hline \multicolumn{8}{|c|}{ Desaturases and other enzymes involved in fatty acid synthesis } \\
\hline AN7111 & $\begin{array}{l}\text { foxA, peroxisomal } \\
\text { multifunctional enzyme } \\
\text { involved in fatty acid } \\
\text { oxidation }^{\mathrm{a}}\end{array}$ & & & & & + & \\
\hline AN9407 & $\begin{array}{l}\text { fas } A \text {, fatty acid synthase, } \\
\text { alpha subunit }^{\text {a }}\end{array}$ & - & - & & & - & - \\
\hline AN4135 & $\begin{array}{l}\text { sdeB, delta-9-stearic acid } \\
\text { desaturase }^{\text {a }}\end{array}$ & - & - & & - & - & - \\
\hline AN1037 & $\begin{array}{l}\text { ode } A \text {, oleate delta- } 12 \\
\text { desaturase }^{\text {a }}\end{array}$ & & - & & & - & - \\
\hline AN7204 & $\begin{array}{l}\text { Putative an2, oleoyl- } \\
\text { delta12 desaturase }\end{array}$ & & - & & & - & \\
\hline
\end{tabular}

a Indicates validated genes by other studies.

These metabolome and transcriptome data suggest that $A$. nidulans requires polyunsaturated fatty acids for membrane formation as well as for $p s i$-factor formation. Furthermore, all genes involved in fatty acid metabolism and psi-factor biosynthesis were expressed at vegetative growth for developmental competency with foxA being the only exception that was upregulated significantly later at S72.

\subsubsection{Light-dependent accumulation of terrequinone, emericellamides} and anthranilate during development of $A$. nidulans

$1 \mathrm{D}-\mathrm{SOM}$ clustering presents an overview of the intensity profiles of a large number of metabolite data at the examined stages of development (Fig. 6A). Here we concentrated on intracellular accumulation of light dependent secondary metabolites (Fig. 6A, Cluster $10-13$ in green frame) and the genetic regulation of the corresponding gene clusters. For the biosynthesis of the antitumor compound terrequinone a gene cluster $(t d i)$ of five genes (tdiA-tdiE; AN8513-AN8517) was identified (Balibar et al., 2007). Four out of these five genes were differentially expressed (Fig. 8B). Whereas the genes coding for the NRPS enzyme ( $t d i A)$ and the asterriquinone prenyltransferase $(t d i B)$ were specifically expressed at both asexual stages, the genes coding for NADPH-dependent quinone reductase $(t d i C)$ and a protein required for terrequinone synthesis (tdiE) were expressed at sexual and asexual development. The metabolite terrequinone $A$ accumulated specifically at asexual development (Fig. 8A).

Further secondary metabolites partially described in A. nidulans were emericellamides initially discovered in marine Emericella $s p$. (Oh et al., 2007). These compounds were also present in A. nidulans (Szewczyk et al., 2008). Emericellamide A, C and E were already present after $24 \mathrm{~h}$ of growth in light, whereas its levels were extremely diminished in darkness at sexual development (Fig. 8A). Light seems to induce or de-repress the production of these antibiotics. Emericellamide levels increased slightly after $48 \mathrm{~h}$ sexual development but never reached the asexual levels. The emericellamide gene cluster comprises four genes easA (AN2545), easB (AN2547), easC (AN2548) and easD (AN2549) important for its synthesis (Chiang et al., 2008). Two eas genes encoding a nonribosomal peptide synthetase (eas $A$ ) and an iterative type I polyketide synthase (eas $B$ ) were constitutively expressed. In contrast, a putative acyltransferase (easC) and an acyl-CoA ligase (easD) were expressed at asexual (A24 and A48) and early and middle sexual (S24 and 

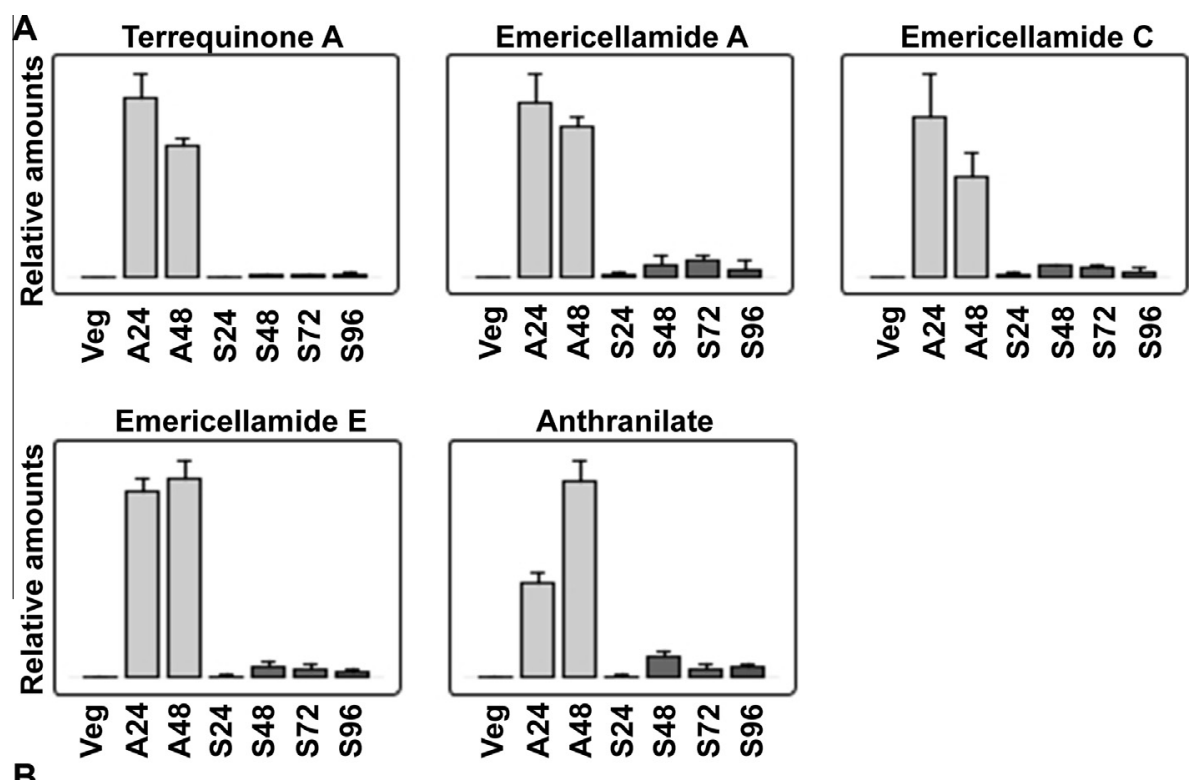

tdi (Terrequinone) gene cluster regulation

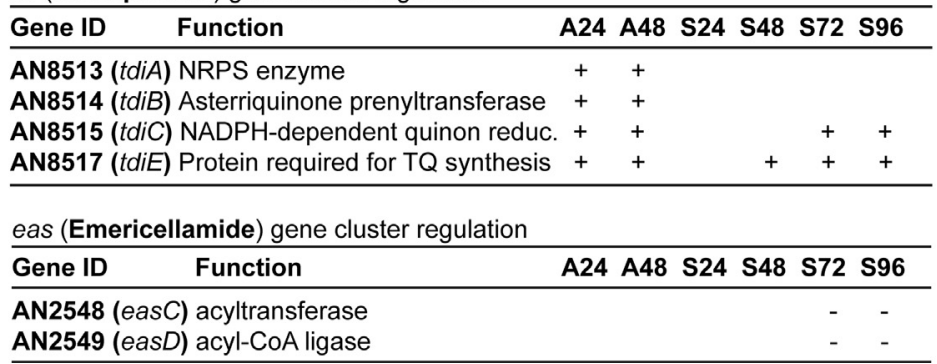

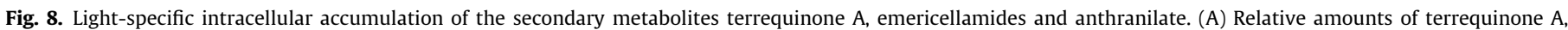

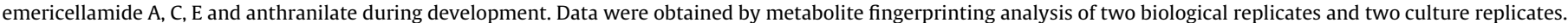

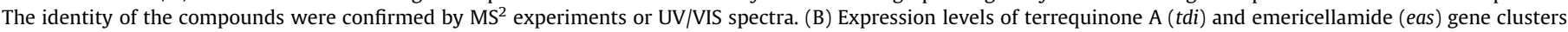

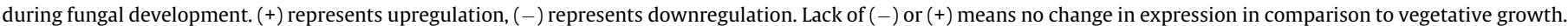

S48) development, but emericellamides A, C and E accumulated mainly during the asexual stage, suggesting that light controls the production of emericellamides by an unknown mechanism.

Anthranilate is a nonproteinogenic amino acid which is an intermediate of tryptophan biosynthesis. In fungi anthranilate plays an important role as building block for the synthesis of nitrogen containing heterocyclic polyketides by NRPS (Walsh et al., 2013). Beside that anthranilate is an important precursor of melanin and involved in the protection of fungus from UV irradiation at asexual development in light. Anthranilate accumulated specifically during asexual development (Fig. 8A). As observed for emericellamide $\mathrm{C}$, anthranilate also appeared intracellularly at both asexual stages and was present in the extracellular metabolome at the end of asexual differentiation A48 (not shown). The identity of emericellamide A, C and E as well as anthranilate were unequivocally confirmed by MS/MS fragmentation experiments with LC/ESI-QTOF-MS (Supplementary data 2). The chemical structure of terrequinone A could be validated by exact mass measurement and confirming the compound specific UV-maxima at 225 and $275 \mathrm{~nm}$ (Bouhired et al., 2007). These data propose that biosynthesis of several secondary metabolites such as terrequinone, emericellamides or anthranilate are triggered by the light signal resulting in their appearance during asexual development.

\subsubsection{Accumulation of sterigmatocystin, asperthecin and derivatives} during sexual development of $A$. nidulans

The metabolite fingerprinting approach led also to the detection of secondary metabolites characteristic for sexual development
(Fig. 6A, Cluster 21-25 in red frame). Sterigmatocystin (ST) was identified as a compound, which was highly accumulated at sexual development (S48 and S72). At late sexual phase S96 ST levels drastically decreased (Fig. 9A). Only small amounts of ST were detected in A24. In contrast to that, the genes of the stc gene cluster required for ST production were mainly expressed at both asexual and late sexual development (Fig. 9B). 13 of 25 known stc genes were differentially expressed. Two exceptions were observed regarding stc gene expression. stcF (AN7818) encoding a P450 monooxygenase was specifically expressed at the asexual stages and disappeared at sexual cycle. A putative peroxidase encoded by stcC (AN7823) was expressed at S48 additionally. The function of StcC has not been characterized yet.

Additionally to ST also asperthecin, its precursor emodin as well as emericellin and shamixanthone were identified as metabolites, which accumulate at later sexual development (Fig. 9A). In accordance with this, many genes required for asperthecin (apt) and monodictyphenone ( $m d p)$ synthesis were rather sexual specific expressed (Fig. 9B). The apt genes within the asperthecin cluster were reported not being expressed at laboratory conditions (Szewczyk et al., 2008). Our data showed apt gene upregulation and an intracellular asperthecin accumulation at late sexual development (S72 and S96). Emodin as precursor of asperthecin was present at sexual stages S48-S96 (Fig. 8B). Because AptC, which catalyzes the conversion of emodin to asperthecin was only expressed at S72, emodin accumulated already at S48 whereas asperthecin levels was still low at this time point. 
A

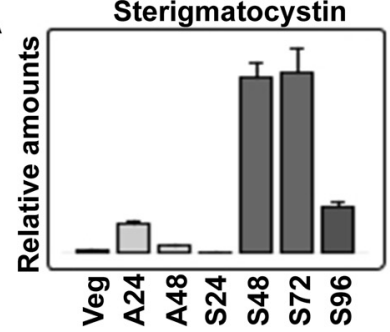

Emericellin

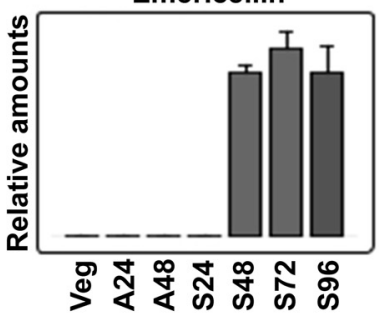

Asperthecin

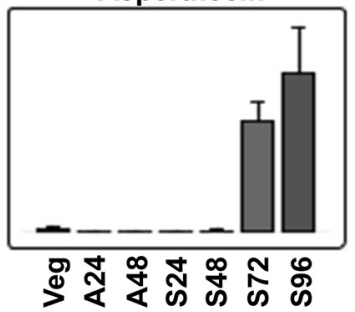

Shamixanthone

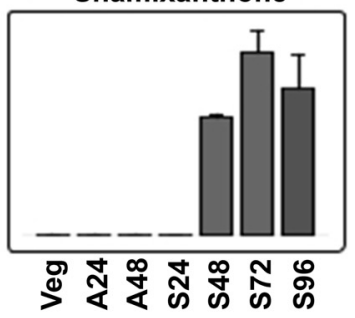

B stc (Sterigmatocysin) gene cluster regulation

\begin{tabular}{|c|c|c|c|c|c|c|c|}
\hline Gene ID & Function & A24 & A48 & S24 & S48 & S72 & S96 \\
\hline AN7804 & $\mathrm{cW}$ FAD-containing monooxygenase & + & + & & & + & + \\
\hline AN7806 & cU) Versicolorin reductase & + & + & & & + & + \\
\hline AN7807 & $c 7)$ Translation elongation factor & + & + & & & + & + \\
\hline AN7810 & $c Q) \mathrm{NADH}$-flavin reductase & + & + & & & + & + \\
\hline AN7812 & $c N)$ Versicolorin B synthase & + & + & & & + & + \\
\hline AN7816 & cl) Lipase/Esterase & + & + & & & + & + \\
\hline AN7817 & characterized dehydrogenase & + & + & & & + & + \\
\hline AN7818 & cF) P450 monooxygenase & + & + & & & & \\
\hline AN7819 & icharacterized w/o domain & + & + & & & + & + \\
\hline AN7820 & IR) Transcription factor & + & + & & & + & + \\
\hline AN7821 & $C E)$ Norsolorinic acid reductase & + & + & & & + & + \\
\hline AN7822 & egral membrane protein & + & + & & & + & + \\
\hline AN7822 & cC) Peroxidase & + & + & & + & + & + \\
\hline
\end{tabular}

apt (Asperthecin) gene cluster regulation

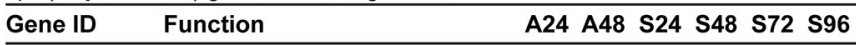

AN6000 (aptA) PKS (polyketide synthase) +

AN6001 (aptB) Hydrolase

AN6002 (aptC) Monooxygenase

$m d p$ (Monodictyphenone) gene cluster regulation

\begin{tabular}{lcc}
\hline Gene ID $\quad$ Function & A24 A48 S24 S48 S72 S96 \\
\hline AN0146 $(m d p C)$ versicolorin ketoreductase & + & + \\
AN0147 $(m d p D)$ Flavin-containing monooxy. & + & + \\
AN0148 $(m d p E)$ AfIR homolog protein & + & + \\
AN0149 $(m d p F)$ Zinc-dependent hydrolase & + \\
AN10022 $(m d p H)$ DUF 1772 superfamily & + \\
AN10023 $(m d p L)$ unknown domain protein & + \\
AN10035 $(m d p l)$ AMP-binding CoA ligase & + \\
AN10038 $(m d p J)$ Glutathione-S-transferase & + \\
AN10044 $(m d p K)$ Oxidoreductase & + \\
AN6784 $(x p t A)$ Prenyltransferase & + \\
\hline
\end{tabular}

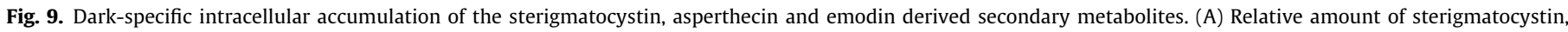

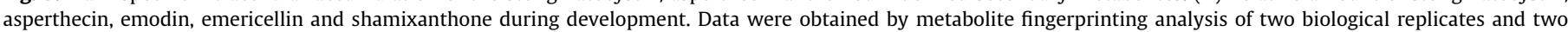

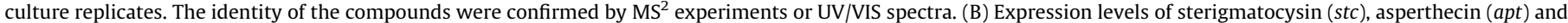

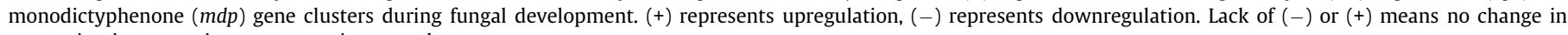
expression in comparison to vegetative growth.

The genes which encode proteins for the monodictyphenone synthesis ( $m d p c, m d p L, m d p I$ and $m d p K$ ) were specifically expressed at S72 (Fig. 8B). Though three of five $m d p$ genes needed for monodictyphenone synthesis were upregulated at S72, monodictyphenone could not be detected by metabolite fingerprinting analysis. In contrast, compounds that share the same biosynthesis pathway with monodictyphenone such as emericellin and shamixanthone were detected at mid and late sexual development S48, S72 and S96 (Fig. 9A). Emericellin and shamixanthone belong to the xanthone family like monodictyphenone and asperthecin. Their biological function is still not known, but they are thought to be antimicrobial compounds (Sanchez et al., 2011). Two genes required for emericellin and shamixanthone synthesis like $m d p D$, xptA were upregulated at late sexual development. Therefore, MdpD converts paeciloxanthone to variecoxanthone and XptA catalyzes the conversion from variecoxanthone to emericellin, which accumulated at mid and late sexual development in $A$. nidulans (Fig. 8A). This finding explains accumulation of emericellin in sexual development but not the shamixanthone enrichment, since the $x p t C$ gene product, responsible for the conversion of emericellin to shamixanthone, was constitutively expressed. 
Protective secondary metabolites synthesized intracellularly by A. nidulans have to be secreted to get to its target e.g. bacterial, fungal and other competitors. Therefore, we performed extracellular metabolomics to get a global view on the accumulation of secondary metabolites (Fig. 6A). Analyses of extracellular metabolomes were restricted to vegetative growth (Veg) and end points of asexual and sexual development (A48, S96). This setup gives us a general overview concerning the metabolites, which were either secreted or accumulated until the end of each development cycle of $A$. nidulans. Despite the highly sexual specific sterigmatocystin (ST) accumulation, only very low amounts of ST could be detected in the culture supernatant (not shown). One reason could be that ST, a metabolite with lipophilic features, was lost during the extraction from supernatant. Generally, ST content was highest in intracellular metabolome at S48. Its content at both stages of asexual development was significantly lower. Although numerous secondary metabolites were produced at sexual development, only emericellamide $C$ could be detected at lower levels in the extracellular environment at S96 (not shown). The identity of emodin was verified by coelution with identical standard (BioViotica Naturstoffe $\mathrm{GmbH}$, Germany). Emericellin and shamixanthone were unequivocally confirmed by MS/MS fragmentation analysis with a LC/ESI-QTOF-MS (Supplementary data 2). The identity of asperthecin could be validated by exact mass measurement and confirming the compound specific UV-maxima at 262, 286, 316 and $485 \mathrm{~nm}$ (Szewczyk et al., 2008).

These results suggest that light specifically influences production of several secondary metabolites at the transcriptional and presumably other regulatory levels, leading to specific patterns of secondary metabolites during fungal morphogenesis both at intracellular and extracellular levels.

\section{Discussion}

Developmental responses of multicellular organisms require complex interactions between gene expression and physiological control mechanism. Fungal development and metabolite production are intriguing processes that are highly controlled by environmental signals. One environmental signal is light that controls morphologic, physiologic and metabolic responses in fungi. A. nidulans has been used as a model organism of development and secondary metabolite production for many years. However, the responses to light and dark have not been previously analyzed in detail at the global developmental level (Ruger-Herreros et al., 2011). Here, we characterized the drastic changes in gene expression and metabolite levels by transcriptomic as well as metabolomic approaches during development of $A$. nidulans. During vegetative growth the fungus expresses primary metabolism as well as saprophytic activity genes to ensure the biosynthesis of plasma membrane, cell wall and continuous growth of the fungal hyphae. One fifth of the genome of $A$. nidulans is differentially expressed during fungal differentiation. The fungus responds to the presence of light and air surface interface quickly whereas there is in the absence of light an almost unresponsive adaptation phase in the first $24 \mathrm{~h}$ of darkness. This adaptation phase results in a 24 or 48 h delay in gene expression during sexual development, which is presumably necessary to initiate and reprogram the dark adapted developmental physiology to proceed in the direction of sexual differentiation. The expression of genes for hormone-like lipid derived psi factors during vegetative growth leads to the biosynthesis of several psi factors with a peak at the beginning of sexual development and this wave of hormones presumably drives sexual development (Fig. 10). Asexual and late sexual stages of development see the most drastic changes including production of secondary metabolites, activation of defense mechanisms, pro- duction of bacterial and plant cell wall degrading enzymes, ROS generation, shutdown of amino acid biosynthesis and translational machineries followed by programmed cell-death. The accurate interplay between these processes leads to the next generation of asexual or sexual spores for dispersal to claim new habitats.

One fifth of the $A$. nidulans genome is differentially regulated during illumination on the plates when asexual development is promoted in comparison to darkness that supports sexual development. This indicates a drastic reprogramming of the gene expression network to foster appropriate developmental responses to either the presence or the lack of a light trigger. Previous studies by Ruger-Herreros and coworkers with $A$. nidulans described changes in 5\% of the Aspergillus genome (533 genes) being differentially expressed in response to short term (30 min light) illumination. Interestingly, in agreement with Ruger-Herreros data, we also found a similar number of genes $(7 \%, 711)$ differentially expressed under light conditions. Our cultures were kept under continuous light for $24 \mathrm{~h}$ and we set the threshold $\log _{2} 1.5$, which might explain the $2 \%$ difference in the number of differentially expressed genes in our transcriptome analysis. Furthermore, our cultures were treated different than Ruger-Herreros et al. Surface grown cultures kept in the dark were exposed to light for short period of time. However, our cultures were grown in submerged culture vegetatively (unresponsive to light) and shifted on plates (responsive) and illuminated for 24 or $48 \mathrm{~h}$. Therefore, there is an influence of other parameters such as $\mathrm{O}_{2} / \mathrm{CO}_{2}$ ratio, which can cause $2 \%$ difference in gene expression. Differentially expressed genes further increases if the cultures are kept under light up to further developmental time point (A48) where almost $10 \%$ of the whole genome (993 genes) is differentially expressed. However, early sexual development shows a lag phase in response to lack of light signal, which results in activation of 194 genes corresponding to $2 \%$ of the whole genome. During this lag phase, the fungus reprograms entire developmental pathways, which results in activation of 1.168 genes ( $11 \%$ of whole genome) at late sexual development (S72). Normally, A. nidulans produces primarily sexual fruiting bodies (cleistothecia) under darkness conditions, but as can be seen (Fig. 1), it also produces asexual conidiospores at the end of sexual developmental program. As reflection for a proper asexual induction by light, asexual specific genes like the cffA were among the delayed genes in the darkness (Table 4). Another asexual specific gene, tmpA encoding a transmembrane flavoprotein involved in conidium formation (Soid-Raggi et al., 2006) exhibits a $48 \mathrm{~h}$ delay in darkness (Table 4 ). There are many delayed genes such as catalase $c p e A$, desaturase odeA and heterokaryon incompatibility gene (Table 4 ) that might be involved in initiation and maintenance of asexual development under sexual conditions. The delay in expression of asexual-associated genes during sexual development might be an insurance mechanism that generates a temporal separation of sexual and asexual propagation to avoid a sudden exhaustion of available nutrients and cell-wall material for both highly energy consuming spore formation processes. These developmental programs require high level of precursors of proteins, carbohydrates and lipids, which is indicated why both developmental processes results in depletion of certain amino acids and expression of cell-wall degrading enzymes which can potentially digest its own cell-wall in addition to bacterial and plant cell wall. For example, ChiB, a classV chitinase, which is required for age-dependent autolysis in $A$. nidulans (Dillon et al., 2005; Erdei et al., 2008; Karlsson and Stenlid, 2008), was one of the delayed genes. Therefore, ChiB and other cell wall degrading enzymes assure fungal nutrient supply and survival even in a nutrient exhausted environment.

It is interesting that cultivation in darkness leads to a somewhat unresponsive situation of at least one day where only $2 \%$ of the whole genome is differentially expressed whereas light induces a 


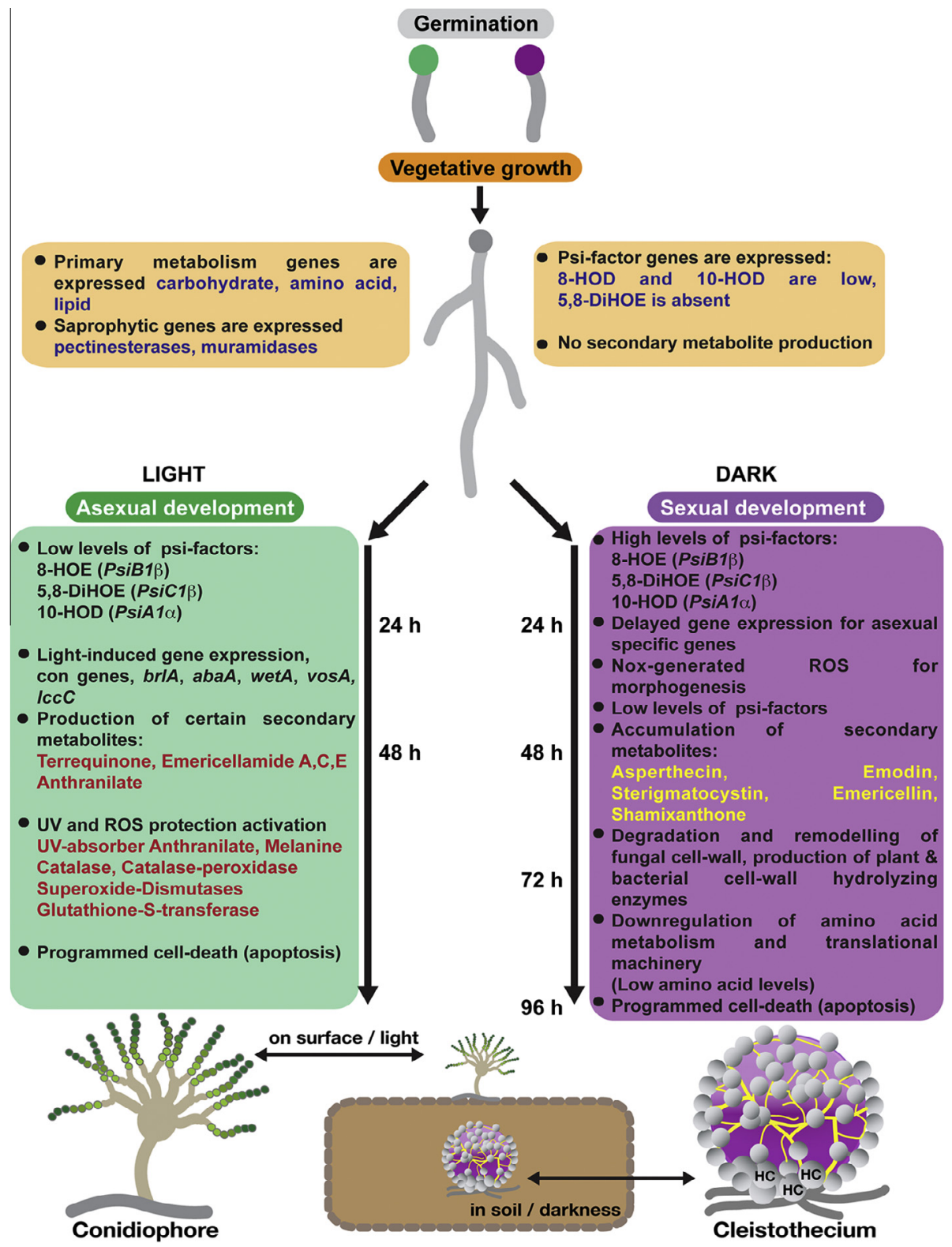

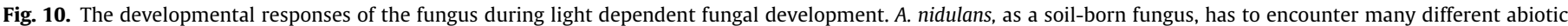

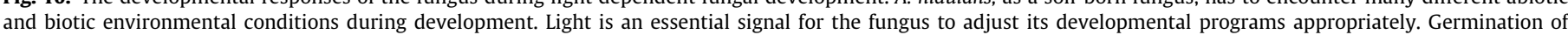

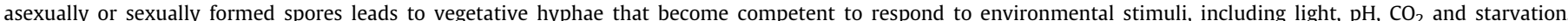

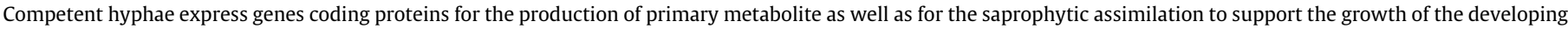

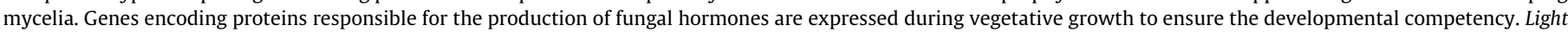

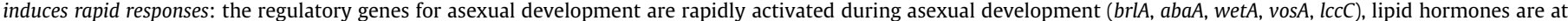

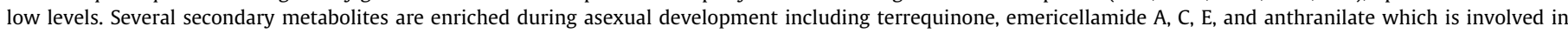

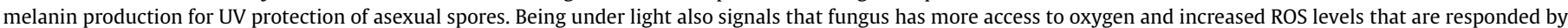

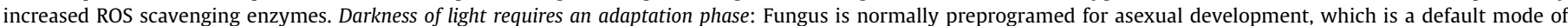

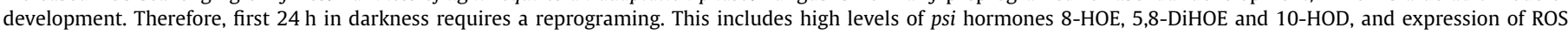

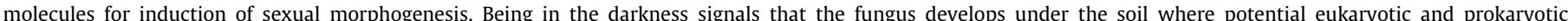

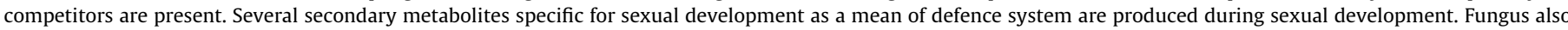

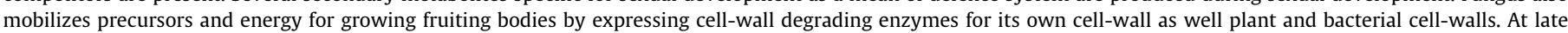

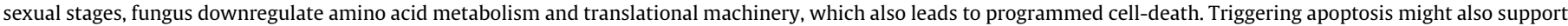
new generation of ascospores by providing lysed cell material as well as secondary metabolites by presumably repelling the predators.

quicker and more drastic response. An interesting question is why such a 24 or 48 h delay takes place during sexual development in darkness when compared to cultivation in light. Fungal development in darkness could be in parts a default program, which can be accelerated and modified by light (Fig. 10). The initial delay might allow the fungus a massive reprogramming at the regulatory level during the first 24 and $48 \mathrm{~h}$ of sexual development. This reprogramming is more evident in genes participating in signal transduction, chromatin control, lipid levels and ROS generating gene expression (Table 4). Genes presumably involved in sensing and signal transduction are specifically downregulated in sexual stages. The red light receptor phytochrome, FphA required for repression of sexual development under red light conditions belong to histidine kinases. There are 9 histidine kinase families 
found in A. nidulans. Four histidine kinases of family 8 are specifically downregulated at early sexual development together with putative green light receptor (opsin) encoding gene nopA (Supplementary data 1: Table S5). Histone acetyl transferases have an activating role in gene expression by acetylating and changing the overall charge of histone proteins, which in turn diminishes the affinity between the DNA and the histone proteins. A. nidulans genome encodes 40 GCN5-related N-acetyltransferase domain proteins (ngn), some of which are involved in activation of asexual conidiation and secondary metabolite gene clusters during cocultivation of $A$. nidulans with Streptomyces ssp (Canovas et al., 2014; Nutzmann et al., 2011). Eight out of 40 ngn genes were upregulated during sexual development, and four out of these eight genes were specific for early sexual development (S24), indicating epigenetic reprogramming during early unresponsive phase of sexual development (Supplementary data 1: Table S6). The influence of the early acetylation of histones presumably leads to further cascade of changes in gene expression during late sexual development (S72 and S96).

Lipid derived fungal hormones ( $p s i$ factors) are one of the major triggers for sexual development, which may also contribute to idle dark response. The three fungal hormones (8-HOE, 10-HOD and 5,8-DiHOE) are accumulated during early sexual stage (S24) when the fungus exhibits unresponsive behavior. Reprogramming requires the fungal hormones, because the levels of these three hormones drops down rapidly after phase, which could indicate that they are involved in reprogramming at early dark stage and degraded or metabolized at later stages (Fig. 10). This degradation of the psi factors is presumably required for the progress of the proper sexual development and they might be used up by the fungal cells by $\beta$-oxidation at further stages. Currently, the receptor/s of these hormones is unknown.

ROS accumulation is required for differentiation and morphogenesis in eukaryotic organisms. Fungal development depends on balanced levels of ROS, which is mediated by enzymes such as ROS generating NADPH oxidases (NOX), or ROS scavenging enzymes catalases, superoxide dismutases (SOD) (Nahlik et al., 2010). NoxA of $A$. nidulans was shown to be required for sexual development (Lara-Ortiz et al., 2003). Specific expression of three putative nox genes during sexual development further supports the requirement of nox genes for sexual differentiation (Tables 1 and 4). Whereas sexual development requires generation of ROS molecules by NOX enzymes, catalase and peroxidases are mainly expressed during asexual sporulation (under light) with cpeA as the only exception that is also present in darkness. The asexual program might not need any ROS generation by the NOX system, because the formation of conidia pigments by phenol oxidases and other enzymes might already generate sufficient amounts of ROS for differentiation during asexual conidiation. Excessive ROS must be either inactivated by scavenging enzymes or triggers programmed cell-death during later stages of fungal development.

An important aspect of secondary metabolite production is that the producer organism protects itself and the surrounding territory from other invaders, including bacteria, protozoa, nematodes, fungi, plants or insects (Doll et al., 2013). Protection against other organisms is an antagonistic process and includes acting and reacting mechanisms. Production and secretion of secondary metabolites is an offensive part of protection, whereas export of toxic metabolites out of fungal cells produced by other competitors in the same habitat is the defensive part of protection. Most secondary metabolite genes are expressed at both late asexual and late sexual stages. Gene expression and production of some secondary metabolites do not always correlate with each other. For instance, the ST gene cluster for the mycotoxin sterigmatocystin is expressed at both asexual and sexual stages, but ST is mostly detected during sexual development. At the protein levels this corresponds to the finding that light inhibits the formation of the trimeric VelB-VeA-LaeA velvet complex which in turn leads to less sterigmatocystin production and less cleistothecia formation during illumination (Bayram et al., 2008b). In contrast to ST, the secondary metabolites emericellamide $\mathrm{A}, \mathrm{C}$ and $\mathrm{E}$, terrequinon and the aromatic compound anthranilate are produced during asexual sporulation. Anthranilate serves as a precursor for melanin production that is stored in asexual conidia and hyphae where it is presumably involved in the protection of fungal spores from UV irradiation under light. The polyketides asperthecin, emodin, emericellin or shamixathone are produced during sexual development where there exact molecular function during development is not yet elucidated in detail.

Primary metabolism is together with the production of secondary metabolites switched off at late sexual stages. This is indicated by downregulation of amino acid biosynthetic genes coinciding with a sharp drop in amino acid levels. Furthermore, this downregulation is also followed by a downregulation in translational genes that drive protein synthesis, which is analogous to the stringent response in bacteria. Finally, the fungus initiates the programmed cell-death pathway. Biological material derived from programmed cell-death might serve as additional food supply for ascospore and conidia formation for the next proliferative fungal generation. Moreover, degradation of polymers during programmed cell-death might also lead to leak of several intracellular metabolites to the environment that can act as chemical shield for the protection of asexual or sexual spores from major predators.

A molecular understanding of the major physiological and metabolic responses of fungi to environmental signals is highly essential to gain further insights into the regulation of development and to control fungal growth for the benefit of agriculture or human health. The production of secondary metabolites is influenced by developmental processes because molecular links as the trimeric velvet complex coordinate fungal development and metabolite production. This study provides an overall snapshot of gene expression and metabolite formation during development in the filamentous fungus $A$. nidulans as a model organism. Similar approaches might be interesting for biotechnologically or medically relevant fungi to understand their metabolic and transcriptional interplay as responses to environmental signals.

\section{Acknowledgments}

This research has been funded by the Deutsche Forschungsgemeinschaft (DFG) to GB and IF (excellence initiative DFG INST 186/822-1) and Science Foundation Ireland (SFI) Grant Number $13 / C D A / 2142$ to OB. We are grateful to Pia Meyer for excellent technical assistance for metabolomics, Lennart Opitz, (DNA Microarray and Deep-Sequencing Facility Goettingen) for microarray analysis and Rainer Bohrer and Oliver Valerius for support in data storage. We are thankful to Jesus Aguirre (Universidad Nacional Autonoma de Mexico) for providing us with Variecoxanthone and to Axel Zeeck (BioViotica Naturstoffe $\mathrm{GmbH}$ ) for providing us with emodin.

\section{Appendix A. Supplementary material}

Supplementary data associated with this article can be found, in the online version, at http://dx.doi.org/10.1016/j.fgb.2016.01.004.

\section{References}

Ahmed, Y.L., Gerke, J., Park, H.S., Bayram, O., Neumann, P., Ni, M., Dickmanns, A., Kim, S.C., Yu, J.H., Braus, G.H., Ficner, R., 2013. The velvet family of fungal 
regulators contains a DNA-binding domain structurally similar to NF-kappaB. PLoS Biol. 11, e1001750.

Balibar, C.J., Howard-Jones, A.R., Walsh, C.T., 2007. Terrequinone A biosynthesis through L-tryptophan oxidation, dimerization and bisprenylation. Nat. Chem. Biol. 3, 584-592.

Bauer, S., Vasu, P., Persson, S., Mort, A.J., Somerville, C.R., 2006. Development and application of a suite of polysaccharide-degrading enzymes for analyzing plant cell walls. Proc. Natl. Acad. Sci. USA 103, 11417-11422.

Bayram, O., Biesemann, C., Krappmann, S., Galland, P., Braus, G.H., 2008a. More than a repair enzyme: Aspergillus nidulans photolyase-like CryA is a regulator of sexual development. Mol. Biol. Cell 19, 3254-3262.

Bayram, O., Braus, G.H., 2012. Coordination of secondary metabolism and development in fungi: the velvet family of regulatory proteins. FEMS Microbiol. Rev. 36, 1-24.

Bayram, O., Braus, G.H., Fischer, R., Rodriguez-Romero, J., 2010. Spotlight on Aspergillus nidulans photosensory systems. Fungal Genet. Biol. 47, 900-908.

Bayram, O., Krappmann, S., Ni, M., Bok, J., Helmstaedt, K., Valerius, O., BrausStromeyer, S., Kwon, N., Keller, N., Yu, J., Braus, G., 2008b. VelB/VeA/LaeA complex coordinates light signal with fungal development and secondary metabolism. Science 320, 1504-1506.

Benjamini, Y., Hochberg, Y., 1995. Controlling the false discovery rate: a practical and powerful approach to multiple testing. J. R. Stat. Soc. 57, 289-300.

Bernstein, B.E., Kamal, M., Lindblad-Toh, K., Bekiranov, S., Bailey, D.K., Huebert, D.J., McMahon, S., Karlsson, E.K., Kulbokas 3rd, E.J., Gingeras, T.R., Schreiber, S.L., Lander, E.S., 2005. Genomic maps and comparative analysis of histone modifications in human and mouse. Cell 120, 169-181.

Blumenstein, A., Vienken, K., Tasler, R., Purschwitz, J., Veith, D., Frankenberg-Dinkel, N., Fischer, R., 2005. The Aspergillus nidulans phytochrome FphA represses sexual development in red light. Curr. Biol. 15, 1833-1838.

Bok, J.W., Keller, N.P., 2004. LaeA, a regulator of secondary metabolism in Aspergillus spp. Eukaryot. Cell 3, 527-535.

Bouhired, S., Weber, M., Kempf-Sontag, A., Keller, N.P., Hoffmeister, D., 2007. Accurate prediction of the Aspergillus nidulans terrequinone gene cluster boundaries using the transcriptional regulator LaeA. Fungal Genet. Biol. 44, $1134-1145$.

Brakhage, A.A., 2013. Regulation of fungal secondary metabolism. Nat. Rev. Microbiol. 11, 21-32.

Bras, M., Queenan, B., Susin, S.A., 2005. Programmed cell death via mitochondria: different modes of dying. Biochemistry (Mosc.) 70, 231-239.

Bretz, F., Landgrebe, J., Brunner, E., 2005. Multiplicity issues in microarray experiments. Meth. Informn. Med. 44, 431-437.

Brodhun, F., Gobel, C., Hornung, E., Feussner, I., 2009. Identification of PpoA from Aspergillus nidulans as a fusion protein of a fatty acid heme dioxygenase/ peroxidase and a cytochrome P450. J. Biol. Chem. 284, 11792-11805.

Brown, D.W., Adams, T.H., Keller, N.P., 1996. Aspergillus has distinct fatty acid synthases for primary and secondary metabolism. Proc. Natl. Acad. Sci. USA 93, $14873-14877$.

Brownell, J.E., Zhou, J., Ranalli, T., Kobayashi, R., Edmondson, D.G., Roth, S.Y., Allis, C. D., 1996. Tetrahymena histone acetyltransferase A: a homolog to yeast Gcn5p linking histone acetylation to gene activation. Cell 84, 843-851.

Calvo, A.M., Gardner, H.W., Keller, N.P., 2001. Genetic connection between fatty acid metabolism and sporulation in Aspergillus nidulans. J. Biol. Chem. 276, $25766-$ 25774.

Canovas, D., Marcos, A.T., Gacek, A., Ramos, M.S., Gutierrez, G., Reyes-Dominguez, Y., Strauss, J., 2014. The histone acetyltransferase GcnE (GCN5) plays a central role in the regulation of Aspergillus asexual development. Genetics.

Champe, S.P., el-Zayat, A.A., 1989. Isolation of a sexual sporulation hormone from Aspergillus nidulans. J. Bacteriol. 171, 3982-3988.

Chelikani, P., Fita, I., Loewen, P.C., 2004. Diversity of structures and properties among catalases. Cell. Mol. Life Sci. 61, 192-208.

Chiang, Y.M., Szewczyk, E., Davidson, A.D., Entwistle, R., Keller, N.P., Wang, C.C., Oakley, B.R., 2010. Characterization of the Aspergillus nidulans monodictyphenone gene cluster. Appl. Environ. Microbiol. 76, 2067-2074.

Chiang, Y.M., Szewczyk, E., Nayak, T., Davidson, A.D., Sanchez, J.F., Lo, H.C., Ho, W.Y., Simityan, H., Kuo, E., Praseuth, A., Watanabe, K., Oakley, B.R., Wang, C.C., 2008. Molecular genetic mining of the Aspergillus secondary metabolome: discovery of the emericellamide biosynthetic pathway. Chem. Biol. 15, 527-532.

Corrochano, L.M., 2011. Fungal photobiology: a synopsis. IMA Fungus 2, 25-28.

Coutinho, P.M., Andersen, M.R., Kolenova, K., vanKuyk, P.A., Benoit, I., Gruben, B.S., Trejo-Aguilar, B., Visser, H., van Solingen, P., Pakula, T., Seiboth, B., Battaglia, E., Aguilar-Osorio, G., de Jong, J.F., Ohm, R.A., Aguilar, M., Henrissat, B., Nielsen, J., Stalbrand, H., de Vries, R.P., 2009. Post-genomic insights into the plant polysaccharide degradation potential of Aspergillus nidulans and comparison to Aspergillus niger and Aspergillus oryzae. Fungal Genet. Biol. 46 (Suppl. 1), S161-S169.

David, H., Ozcelik, I.S., Hofmann, G., Nielsen, J., 2008. Analysis of Aspergillus nidulans metabolism at the genome-scale. BMC Genom. 9, 163.

Dillon, S.C., Zhang, X., Trievel, R.C., Cheng, X., 2005. The SET-domain protein superfamily: protein lysine methyltransferases. Genome Biol. 6, 227.

Dirschnabel, D.E., Nowrousian, M., Cano-Dominguez, N., Aguirre, J., Teichert, I., Kuck, U., 2014. New insights into the roles of NADPH oxidases in sexual development and ascospore germination in Sordaria macrospora. Genetics 196, 729-744.

Doll, K., Chatterjee, S., Scheu, S., Karlovsky, P., Rohlfs, M., 2013. Fungal metabolic plasticity and sexual development mediate induced resistance to arthropod fungivory. Proc. Biol. Sci. R. Soc. 280, 20131219.
Eckert, S.E., Hoffmann, B., Wanke, C., Braus, G.H., 1999. Sexual development of Aspergillus nidulans in tryptophan auxotrophic strains. Arch. Microbiol. 172 157-166.

Erdei, E., Pusztahelyi, T., Miskei, M., Barna, T., Pocsi, I., 2008. Characterization and heterologous expression of an age-dependent fungal/bacterial type chitinase of Aspergillus nidulans. Acta Microbiol. Immunol. Hung. 55, 351-361.

Etxebeste, O., Garzia, A., Espeso, E.A., Ugalde, U., 2010. Aspergillus nidulans asexual development: making the most of cellular modules. Trends Microbiol. 18, 569576.

Fahey, R.C., 2001. Novel thiols of prokaryotes. Annu. Rev. Microbiol. 55, 333-356.

Floerl, S., Majcherczyk, A., Possienke, M., Feussner, K., Tappe, H., Gatz, C., Feussner, I., Kues, U., Polle, A., 2012. Verticillium longisporum infection affects the leaf apoplastic proteome, metabolome, and cell wall properties in Arabidopsis thaliana. PLoS One 7, e31435.

Galagan, J.E., Calvo, S.E., Cuomo, C., Ma, L.J., Wortman, J.R., Batzoglou, S., Lee, S.I., Basturkmen, M., Spevak, C.C., Clutterbuck, J., Kapitonov, V., Jurka, J., Scazzocchio, C., Farman, M., Butler, J., Purcell, S., Harris, S., Braus, G.H., Draht, O., Busch, S., D’Enfert, C., Bouchier, C., Goldman, G.H., Bell-Pedersen, D., Griffiths-Jones, S., Doonan, J.H., Yu, J., Vienken, K., Pain, A., Freitag, M., Selker, E.U., Archer, D.B. Penalva, M.A., Oakley, B.R., Momany, M., Tanaka, T., Kumagai, T., Asai, K. Machida, M., Nierman, W.C., Denning, D.W., Caddick, M., Hynes, M., Paoletti, M., Fischer, R., Miller, B., Dyer, P., Sachs, M.S., Osmani, S.A., Birren, B.W., Eckert, S.E., Krappmann, S., 2005. Sequencing of Aspergillus nidulans and comparative analysis with A. fumigatus and A. oryzae. Nature 438, 1105-1115.

Gallagher, L., Owens, R.A., Dolan, S.K., O’Keeffe, G., Schrettl, M., Kavanagh, K., Jones, G.W., Doyle, S., 2012. The Aspergillus fumigatus protein GliK protects against oxidative stress and is essential for gliotoxin biosynthesis. Eukaryot. Cell 11 1226-1238.

Garscha, U., Jerneren, F., Chung, D., Keller, N.P., Hamberg, M., Oliw, E.H., 2007. Identification of dioxygenases required for Aspergillus development. Studies of products, stereochemistry, and the reaction mechanism. J. Biol. Chem. 282, 34707-34718.

Giles, S.S., Soukup, A.A., Lauer, C., Shaaban, M., Lin, A., Oakley, B.R., Wang, C.C. Keller, N.P., 2011. Cryptic Aspergillus nidulans antimicrobials. Appl. Environ. Microbiol. 77, 3669-3675.

Hoffmann, B., Valerius, O., Andermann, M., Braus, G.H., 2001. Transcriptional autoregulation and inhibition of mRNA translation of amino acid regulator gene сpcA of filamentous fungus Aspergillus nidulans. Mol. Biol. Cell 12, 2846-2857.

Hoffmann, M., Hornung, E., Busch, S., Kassner, N., Ternes, P., Braus, G.H., Feussner, I. 2007. A small membrane-peripheral region close to the active center determines regioselectivity of membrane-bound fatty acid desaturases from Aspergillus nidulans. J. Biol. Chem. 282, 26666-26674.

Huber, W., von Heydebreck, A., Sultmann, H., Poustka, A., Vingron, M., 2002. Variance stabilization applied to microarray data calibration and to the quantification of differential expression. Bioinformatics 18 (Suppl. 1), S96S104.

Junker, B.H., Klukas, C., Schreiber, F., 2006. VANTED: a system for advanced data analysis and visualization in the context of biological networks. BMC Bioinform. 7, 109.

Kaever, A., Landesfeind, M., Feussner, K., Mosblech, A., Heilmann, I., Morgenstern, B. Feussner, I., Meinicke, P., 2015. MarVis-pathway: integrative and exploratory pathway analysis of non-targeted metabolomics data. Metabolomics 11, 764777.

Kaever, A., Lingner, T., Feussner, K., Gobel, C., Feussner, I., Meinicke, P., 2009. MarVis: a tool for clustering and visualization of metabolic biomarkers. BMC Bioinform. $10,92$.

Karlsson, M., Stenlid, J., 2008. Comparative evolutionary histories of the fungal chitinase gene family reveal non-random size expansions and contractions due to adaptive natural selection. Evol. Bioinform. 4, 47-60.

Kawasaki, L., Aguirre, J., 2001. Multiple catalase genes are differentially regulated in Aspergillus nidulans. J. Bacteriol. 183, 1434-1440.

Kawasaki, L., Wysong, D., Diamond, R., Aguirre, J., 1997. Two divergent catalase genes are differentially regulated during Aspergillus nidulans development and oxidative stress. J. Bacteriol. 179, 3284-3292.

Keller, N.P., Turner, G., Bennett, J.W., 2005. Fungal secondary metabolism - from biochemistry to genomics. Nat. Rev. Microbiol. 3, 937-947.

Landgrebe, J., Bretz, F., Brunner, E., 2004. Efficient two-sample designs for microarray experiments with biological replications. In Silico Biol. 4, 461-470.

Lara-Ortiz, T., Riveros-Rosas, H., Aguirre, J., 2003. Reactive oxygen species generated by microbial NADPH oxidase NoxA regulate sexual development in Aspergillus nidulans. Mol. Microbiol. 50, 1241-1255.

MacIntosh, G.C., Bariola, P.A., Newbigin, E., Green, P.J., 2001. Characterization of Rny1, the Saccharomyces cerevisiae member of the T2 RNase family of RNases: unexpected functions for ancient enzymes? Proc. Natl. Acad Sci USA 98, 1018 1023.

Maggio-Hall, L.A., Keller, N.P., 2004. Mitochondrial beta-oxidation in Aspergillus nidulans. Mol. Microbiology. 54, 1173-1185.

Marquez-Fernandez, O., Trigos, A., Ramos-Balderas, J.L., Viniegra-Gonzalez, G., Deising, H.B., Aguirre, J., 2007. Phosphopantetheinyl transferase CfwA/NpgA is required for Aspergillus nidulans secondary metabolism and asexual development. Eukaryot. Cell 6, 710-720.

Matyash, V., Liebisch, G., Kurzchalia, T.V., Shevchenko, A., Schwudke, D., 2008. Lipid extraction by methyl-tert-butyl ether for high-throughput lipidomics. J. Lipid Res. 49, 1137-1146.

Nahlik, K., Dumkow, M., Bayram, O., Helmstaedt, K., Busch, S., Valerius, O., Gerke, J. Hoppert, M., Schwier, E., Opitz, L., Westermann, M., Grond, S., Feussner, K., 
Goebel, Kaever, A., Meinicke, P., Feussner, I., Braus, G.H., 1974. The COP9 signalosome mediates transcriptional and metabolic response to hormones, oxidative stress protection and cell wall rearrangement during fungal development. Mol. Microbiol. 78, 964-979.

Navarro, R.E., Stringer, M.A., Hansberg, W., Timberlake, W.E., Aguirre, J., 1996. CatA a new Aspergillus nidulans gene encoding a developmentally regulated catalase. Curr. Genet. 29, 352-359.

Nierman, W.C., Pain, A., Anderson, M.J., Wortman, J.R., Kim, H.S., Arroyo, J., Berriman, M., Abe, K., Archer, D.B., Bermejo, C., Bennett, J., Bowyer, P., Chen, D., Collins, M., Coulsen, R., Davies, R., Dyer, P.S., Farman, M., Fedorova, N., Feldblyum, T.V., Fischer, R., Fosker, N., Fraser, A., Garcia, J.L., Garcia, M.J., Goble, A., Goldman, G.H., Gomi, K., Griffith-Jones, S., Gwilliam, R., Haas, B., Haas, H., Harris, D., Horiuchi, H., Huang, J., Humphray, S., Jimenez, J., Keller, N., Khouri, H., Kitamoto, K., Kobayashi, T., Konzack, S., Kulkarni, R., Kumagai, T., Lafon, A., Latge, J.P., Li, W. Lord, A., Lu, C., Majoros, W.H., May, G.S., Miller, B.L., Mohamoud, Y., Molina, M., Monod, M. Mouyna, I., Mulligan, S., Murphy, L, O'Neil, S., Paulsen, I. Penalva, M. A., Pertea, M., Price, C., Pritchard, B.L., Quail, M.A., Rabbinowitsch, E., Rawlins, N., Rajandream, M.A., Reichard, U., Renauld, H., Robson, G.D., Rodriguez de Cordoba, S., Rodriguez-Pena, J.M., Ronning, C.M., Rutter, S., Salzberg, S.L., Sanchez, M., Sanchez-Ferrero, J.C., Saunders, D., Seeger, K., Squares, R., Squares, S., Takeuchi, M., Tekaia, F., Turner, G., Vazquez de Aldana, C.R., Weidman, J., White, O. Woodward, J., Yu, J.H., Fraser, C., Galagan, J.E., Asai, K., Machida, M., Hall, N. Barrell, B., Denning, D.W., 2005. Genomic sequence of the pathogenic and allergenic filamentous fungus Aspergillus fumigatus. Nature 438, 1151-1156.

Nutzmann, H.W., Reyes-Dominguez, Y., Scherlach, K., Schroeckh, V., Horn, F., Gacek A., Schumann, J., Hertweck, C., Strauss, J., Brakhage, A.A., 2011. Bacteria-induced natural product formation in the fungus Aspergillus nidulans requires Saga/Adamediated histone acetylation. Proc. Natl. Acad. Sci. USA 108, 14282-14287.

Oh, D.C., Kauffman, C.A., Jensen, P.R., Fenical, W., 2007. Induced production of emericellamides A and B from the marine-derived fungus Emericella sp. in competing co-culture. J. Nat. Prod. 70, 515-520.

Purschwitz, J., Muller, S., Kastner, C., Schoser, M., Haas, H., Espeso, E.A., Atoui, A. Calvo, A.M., Fischer, R., 2008. Functional and physical interaction of blue- and red-light sensors in Aspergillus nidulans. Curr. Biol. 18, 255-259.

Rodriguez-Romero, J., Hedtke, M., Kastner, C., M,ller, S., Fischer, R., 2010. Fungi, hidden in soil or up in the air: light makes a difference. Annu. Rev. Microbiol. 64, $585-610$.

Ruger-Herreros, C., Rodriguez-Romero, J., Fernandez-Barranco, R., Olmedo, M. Fischer, R., Corrochano, L.M., Canovas, D., 2011. Regulation of conidiation by light in Aspergillus nidulans. Genetics 188, 809-822.

Sanchez, J.F., Chiang, Y.M., Szewczyk, E., Davidson, A.D., Ahuja, M., Elizabeth Oakley, C., Woo Bok, J., Keller, N., Oakley, B.R., Wang, C.C., 2010. Molecular genetic analysis of the orsellinic acid/F9775 gene cluster of Aspergillus nidulans. Mol. Biosyst. 6, 587-593.

Sanchez, J.F., Entwistle, R., Hung, J.H., Yaegashi, J., Jain, S., Chiang, Y.M., Wang, C.C. Oakley, B.R., 2011. Genome-based deletion analysis reveals the prenyl xanthone biosynthesis pathway in Aspergillus nidulans. J. Am. Chem. Soc. 133, 4010-4017.

Sarikaya Bayram, O., Bayram, O., Valerius, O., Park, H.S., Irniger, S., Gerke, J., Ni, M. Han, K.H., Yu, J.H., Braus, G.H., 2010. LaeA control of velvet family regulatory proteins for light-dependent development and fungal cell-type specificity. PLoS Genet. 6, e1001226.

Sarikaya-Bayram, O., Bayram, O., Feussner, K., Kim, J.H., Kim, H.S., Kaever, A. Feussner, I., Chae, K.S., Han, D.M., Han, K.H., Braus, G.H., 2014. Membrane-bound methyltransferase complex VapA-VipC-VapB guides epigenetic control of fungal development. Develop. Cell 29, 406-420.

Scherer, M., Fischer, R., 1998. Purification and characterization of laccase II of Aspergillus nidulans. Arch. Microbiol. 170, 78-84.

Scherer, M., Wei, H., Liese, R., Fischer, R., 2002. Aspergillus nidulans catalaseperoxidase gene (cpeA) is transcriptionally induced during sexual development through the transcription factor StuA. Eukaryot. Cell 1, 725-735.

Schmelz, E.A., Huffaker, A., Sims, J.W., Christensen, S.A., Lu, X., Okada, K., Peters, R.J., 2014. Biosynthesis, elicitation and roles of monocot terpenoid phytoalexins. Plant J. 79, 659-678.

Schroeckh, V., Scherlach, K., Nutzmann, H.W., Shelest, E., Schmidt-Heck, W. Schuemann, J., Martin, K., Hertweck, C., Brakhage, A.A., 2009. Intimate bacterial-fungal interaction triggers biosynthesis of archetypal polyketides in Aspergillus nidulans. Proc. Natl. Acad. Sci. USA 106, 14558-14563.

Smyth, G.K., 2004. Linear models and empirical bayes methods for assessing differential expression in microarray experiments. Statistical Applications in Genetics and Molecular Biology. 3, Article3.

Soid-Raggi, G., Sanchez, O., Aguirre, J., 2006. TmpA, a member of a novel family of putative membrane flavoproteins, regulates asexual development in Aspergillus nidulans. Mol. Microbiol. 59, 854-869.

Suzuki, S., Sarikaya Bayram, O., Bayram, O., Braus, G.H., 2013. ConF and con] contribute to conidia germination and stress response in the filamentous fungus Aspergillus nidulans. Fungal Genet. Biol. 56, 42-53.

Szewczyk, E., Chiang, Y.M., Oakley, C.E., Davidson, A.D., Wang, C.C., Oakley, B.R., 2008. Identification and characterization of the asperthecin gene cluster of Aspergillus nidulans. Appl. Environ. Microbiol. 74, 7607-7612.

Thompson, D.M., Parker, R., 2009. The RNase Rny1p cleaves tRNAs and promotes cell death during oxidative stress in Saccharomyces cerevisiae. J. Cell Biol. 185, 43-50.

Tsitsigiannis, D.I., Keller, N.P., 2006. Oxylipins act as determinants of natural product biosynthesis and seed colonization in Aspergillus nidulans. Mol. Microbiol. 59, 882-892.

Tsitsigiannis, D.I., Kowieski, T.M., Zarnowski, R., Keller, N.P., 2004a. Endogenous lipogenic regulators of spore balance in Aspergillus nidulans. Eukaryot. Cell 3, $1398-1411$.

Tsitsigiannis, D.I., Kowieski, T.M., Zarnowski, R., Keller, N.P., 2005. Three putative oxylipin biosynthetic genes integrate sexual and asexual development in Aspergillus nidulans. Microbiology 151, 1809-1821.

Tsitsigiannis, D.I., Zarnowski, R., Keller, N.P., 2004b. The lipid body protein, PpoA, coordinates sexual and asexual sporulation in Aspergillus nidulans. J. Biol. Chem. 279, 11344-11353.

Tuncher, A., Reinke, H., Martic, G., Caruso, M.L., Brakhage, A.A., 2004. A basic-region helix-loop-helix protein-encoding gene (devR) involved in the development of Aspergillus nidulans. Mol. Microbiol. 52, 227-241.

Walsh, C.T., Haynes, S.W., Ames, B.D., Gao, X., Tang, Y., 2013. Short pathways to complexity generation: fungal peptidyl alkaloid multicyclic scaffolds from anthranilate building blocks. ACS Chem. Biol. 8, 1366-1382.

Wei, H., Scherer, M., Singh, A., Liese, R., Fischer, R., 2001. Aspergillus nidulans alpha1,3 glucanase (mutanase), mutA, is expressed during sexual development and mobilizes mutan. Fungal Genet. Biol. 34, 217-227.

Wei, H., Vienken, K., Weber, R., Bunting, S., Requena, N., Fischer, R., 2004. A putative high affinity hexose transporter, hxtA, of Aspergillus nidulans is induced in vegetative hyphae upon starvation and in ascogenous hyphae during cleistothecium formation. Fungal Genet. Biol. 41, 148-156.

Wei, W., McCusker, J.H., Hyman, R.W., Jones, T., Ning, Y., Cao, Z., Gu, Z., Bruno, D. Miranda, M., Nguyen, M., Wilhelmy, J., Komp, C., Tamse, R., Wang, X., Jia, P., Luedi, P., Oefner, P.J., David, L., Dietrich, F.S., Li, Y., Davis, R.W., Steinmetz, L.M., 2007. Genome sequencing and comparative analysis of Saccharomyces cerevisiae strain YJM789. Proc. Natl. Acad. Sci USA 104, 12825-12830.

Wissing, S., Ludovico, P., Herker, E., Buttner, S., Engelhardt, S.M., Decker, T., Link, A., Proksch, A., Rodrigues, F., Corte-Real, M., Frohlich, K.U., Manns, J., Cande, C., Sigrist, S.J., Kroemer, G., Madeo, F., 2004. An AIF ortholog regulates apoptosis in yeast. J. Cell Biol. 166, 969-974.

Yang, Y.H., Dudoit, S., Luu, P., Lin, D.M., Peng, V., Ngai, J., Speed, T.P., 2002. Normalization for cDNA microarray data: a robust composite method addressing single and multiple slide systematic variation. Nucl. Acids Res. 30, e15.

Zonneveld, B.J., 1971. Biochemical analysis of the cell wall of Aspergillus nidulans. Biochim. Biophys. Acta 249, 506-514.

Zonneveld, B.J., 1972. Morphogenesis in Aspergillus nidulans. The significance of a alpha-1,3-glucan of the cell wall and alpha-1,3-glucanase for cleistothecium development. Biochim. Biophys. Acta 273, 174-187.

Zonneveld, B.J., 1974. Alpha-1,3 glucan synthesis correlated with alpha-1,3 glucanase synthesis, conidiation and fructification in morphogenetic mutants of Aspergillus nidulans. J. Gen. Microbiol. 81, 445-451. 